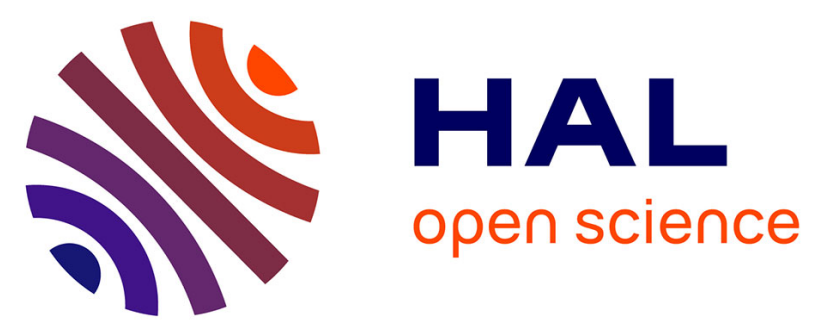

\title{
Influence of acid-base properties of Mg-based catalysts on transesterification: role of magnesium silicate hydrate formation
}

Damien Cornu, Longfei Lin, Maya Mounir Daou, Maguy Jaber, Jean-Marc Krafft, Virginie Herledan, Guillaume Laugel, Yannick Millot, Hélène Lauron-Pernot

\section{To cite this version:}

Damien Cornu, Longfei Lin, Maya Mounir Daou, Maguy Jaber, Jean-Marc Krafft, et al.. Influence of acid-base properties of Mg-based catalysts on transesterification: role of magnesium silicate hydrate formation. Catalysis science and Technology, 2017, 7 (8), pp.1701-1712. 10.1039/C6CY02604D . hal-01547299

\section{HAL Id: hal-01547299 \\ https://hal.sorbonne-universite.fr/hal-01547299}

Submitted on 21 Sep 2018

HAL is a multi-disciplinary open access archive for the deposit and dissemination of scientific research documents, whether they are published or not. The documents may come from teaching and research institutions in France or abroad, or from public or private research centers.
L'archive ouverte pluridisciplinaire HAL, est destinée au dépôt et à la diffusion de documents scientifiques de niveau recherche, publiés ou non, émanant des établissements d'enseignement et de recherche français ou étrangers, des laboratoires publics ou privés. 


\section{Influence of acid-base properties of Mg-based catalysts in transesterification. Role of Magnesium Silicate Hydrate formation.}

Damien Cornu ${ }^{l, \#}$, Longfei Lin $^{l}$, Maya Daou ${ }^{l}$, Maguy Jaber ${ }^{l, 2}$, Jean-Marc Krafft ${ }^{l}$, Virginie Herledan ${ }^{l}$, Guillaume Laugel ${ }^{1}$, Yannick Millot ${ }^{1}$, Hélène Lauron-Pernot ${ }^{1, *}$

${ }^{1}$ Sorbonne Universités, UPMC Univ Paris 06, UMR CNRS 7197, Laboratoire de Réactivité

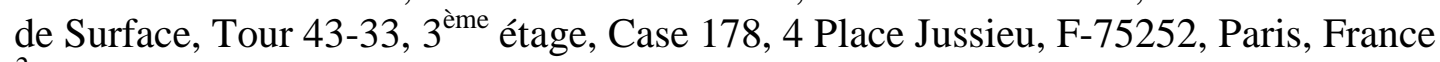

${ }^{2}$ Sorbonne Universités, UPMC Univ Paris 06, UMR CNRS 8220, Laboratoire d'Archéologie Moléculaire et Structurale, Tour 23-33, 3ème étage, Case 225, 4 Place Jussieu, F-75252, Paris, France

* helene.pernot@upmc.fr

Supporting information for this article is given via a link at the end of the document

\section{Abstract}

Transesterification reaction assisted through heterogeneous basic catalysis was thoroughly studied because of its importance to transform biomass, as for biodiesel production or lactone opening. As the catalysts with the strongest basic properties are not always the most efficient ones, a series of magnesium based materials, exhibiting a large range of acido-basic properties, was investigated. Moreover, in order to compare gas and liquid phase operating conditions, a model reaction (transesterification of ethyl acetate with methanol) was chosen. It appears that gas phase transesterification (at $393 \mathrm{~K}$ ) requires strong basic sites whereas magnesium silicate, exhibiting moderate basicity together with acidic properties is a very reactive catalyst in liquid phase (at $333 \mathrm{~K}$ ) depending on its preparation method. The set of experimental data (XRD, XPS, DRIFTS, MEB, ${ }^{29} \mathrm{Si}$ and ${ }^{25} \mathrm{Mg}$ NMR) demonstrated that a magnesium silicate hydrate structure (MSH) is formed at the surface of the most active silicates. It is thus concluded that different mechanisms operate in gas and liquid conditions, and that among the magnesium silicates materials, MSH phase exhibits specific acido-basic properties beneficial to this kind of reaction.

Present address:

\# Foundation ICIQ Avda. Països Catalans, 1643007 Tarragona, Spain 


\section{Graphical TOC}
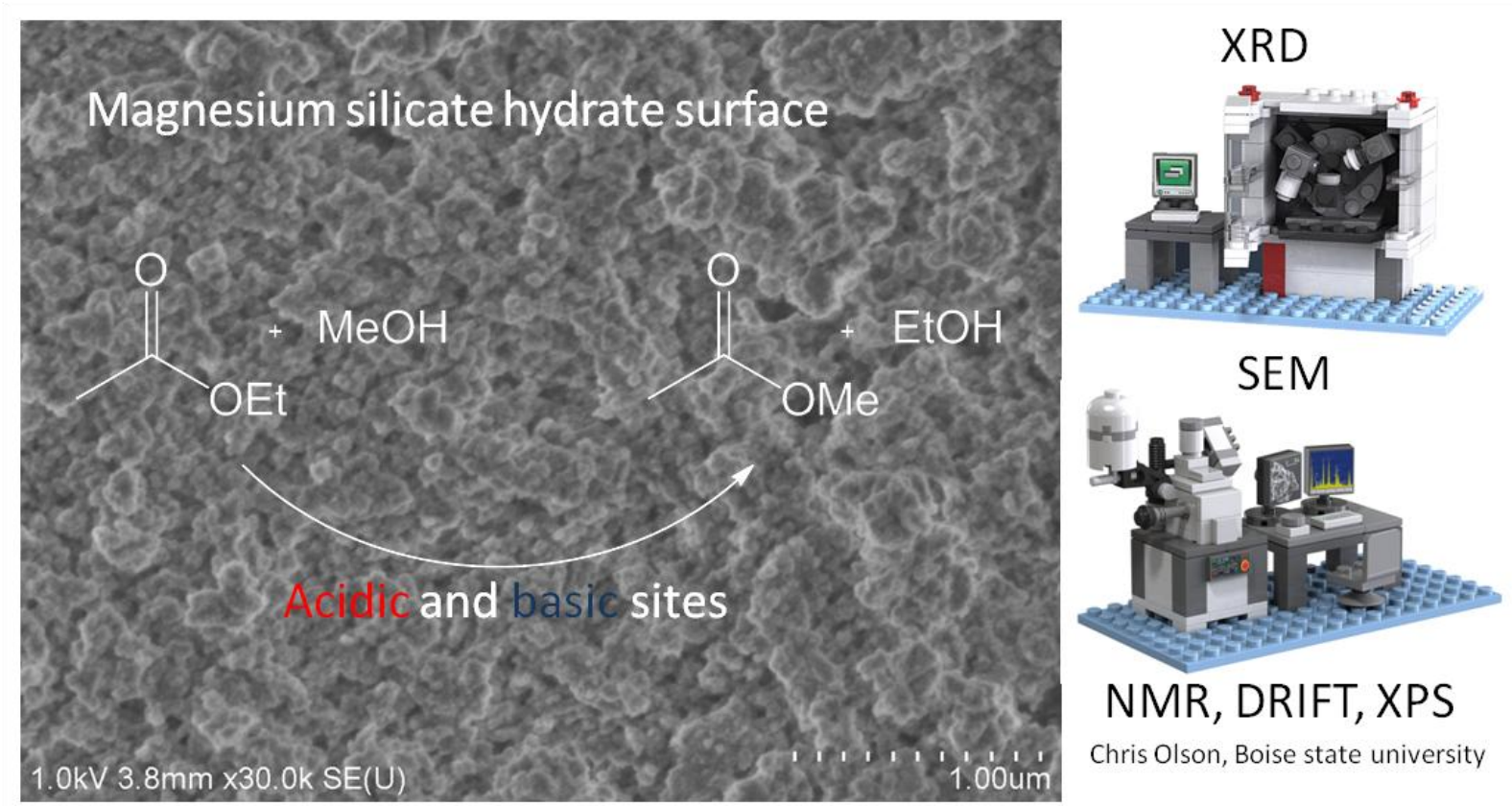

Chris Olson, Boise state university

\section{Introduction}

Numerous heterogeneous catalysts are claimed to catalyze the transesterification reaction. This chemical transformation is widely described for biodiesel production in liquid phase but also involved in gas phase for lactone opening or for various substrate transformation. ${ }^{[1,2]}$ Among them, materials possessing basic properties have gained more attention compared to the acidic materials due to their higher reaction rate. The most common ones are the calcium and magnesium oxides. Their activities in the transesterification reaction were widely reported ${ }^{[3-7]}$ and they are already used in various industrial processes. ${ }^{[8]}$ Their reactivity can be enhanced or decreased by covering the surface with adsorbates $\left(\mathrm{CO}_{2}\right.$ and $\left.\mathrm{H}_{2} \mathrm{O}\right) .{ }^{[9,10]}$ Alkaline earth materials exhibit strong basic sites, but it has also been shown that other solids with weaker surface basicity are able to catalyze this reaction. For instance, biodiesel production can be achieved using potassium carbonate or phosphate, ${ }^{[11,12]}$ barium hydroxide, ${ }^{[5]}$ or zinc based materials ${ }^{[13,14]}$ while calcium and barium acetate enable the 
transesterification of lactones. ${ }^{[15]}$ Moreover, silicates are good catalysts for transesterification, used directly combined with magnesium ${ }^{[16]}$ or as clay minerals, combined with aluminum, calcium and sodium. ${ }^{[17-23]}$ For instance, montmorillonite, belonging to the smectite group, exchanged with lithium hydroxide converts efficiently methyl laurate with glycerol. ${ }^{[18]}$ It thus appears that the influence of the basic strength of a solid is not necessarily correlated with its ability to catalyze the transesterification reaction.

In a previous publication, a model reaction of transesterification between methanol and ethyl acetate was chosen to be able to compare the catalysts behavior both in liquid and in gas phases. ${ }^{[10]}$ The catalyst studied was $\mathrm{MgO}$ with a surface with various coverages of natural adsorbates (hydroxyl groups and carbonates), thus different surface acid-base properties. The transesterification activity in liquid phase was correlated with the so-called "kinetic basicity", evaluated by the ability to isomerize an alkene molecule. ${ }^{[10]}$ This was in line with the proposed mechanisms in the literature for this reaction, involving an adsorption/deprotonation of the alcohol as rate determining step in liquid phase. ${ }^{[3]}$ On the other side, gas phase transesterification seemed to follow a different reaction pathway, as this correlation was not be observed. The aim of the present study is to further investigate the links between acidobasic properties and the activity in transesterification reaction in order to determine if the conclusions obtained on $\mathrm{MgO}$ can be generalized to other kinds of magnesium based materials.

For that purpose, other ionic solids are prepared and tested, keeping the same cation magnesium- and varying the anions: oxide $\left(\mathrm{O}^{2-}\right)$, hydroxide $\left(\mathrm{HO}^{-}\right)$, carbonate $\left(\mathrm{CO}_{3}{ }^{2-}\right)$, phosphate $\left(\mathrm{PO}_{4}{ }^{3-}\right)$, oxalate $\left(\mathrm{C}_{2} \mathrm{O}_{4}{ }^{2-}\right)$ and silicate $\left(\mathrm{SiO}_{4}{ }^{4-}\right)$. In this last case, the properties of a commercial magnesium silicate (Magnesol®) is compared with two laboratory made samples (by co-precipitation or by sol-gel method) and with a typical clay mineral, the montmorillonite. As these materials may exhibit quite weak basic sites and even acidic ones, their surface acido-basic properties are investigated by the conversion of 2-methylbut-3-yn-2- 
ol $(\mathrm{MBOH})$ which is a known model reaction that enable to distinguish between acidic and basic sites. ${ }^{[24]}$ Then, the materials are tested as catalysts of the transesterification of ethyl acetate with methanol both in liquid and gas phases. The link between basic reactivity and the reactivity in the transesterification reaction in the two phases will be discussed in relation to the physico-chemical characterization of the materials.

\section{Experimental section}

\subsection{Preparation of catalysts}

Syntheses were adapted from the literature, trying to minimize the impurities left on the catalysts surfaces and ensuring a specific surface area (SSA) not too small, ideally around $100 \mathrm{~m}^{2} \cdot \mathrm{g}^{-1}$. Values of SSA obtained are given in Tables $1 \mathrm{a}$ and $1 \mathrm{~b}$.

$\operatorname{Mg}(\mathbf{O H})_{2}$ : was obtained from $\operatorname{Mg}\left(\mathrm{NO}_{3}\right)_{2}$ (Sigma-Aldrich, 99,99\%) solution (1 mol.L $\left.{ }^{-1}\right)$ using ammonium hydroxide (Sigma-Aldrich, $99 \%)$ solution $\left(8 \mathrm{~mol} . \mathrm{L}^{-1}\right)$ as precipitating agent. The latter was added to a $100 \mathrm{~mL}$ magnesium nitrate solution until the $\mathrm{pH}$ value reaches the value of 10 at $303 \mathrm{~K}$. After stirring for $30 \mathrm{~min}$, the precipitate was washed 5 times with double distilled water, then dried at $333 \mathrm{~K}$ vacuum for $3 \mathrm{~h}$ (from Bailly et al. ${ }^{[25]}$ )

MgO: $\operatorname{Mg}(\mathrm{OH})_{2}$ was treated under vacuum (1 Torr) up to $1273 \mathrm{~K}$ (ramp $1 \mathrm{~K}^{\mathrm{m}} \mathrm{min}^{-1}$ ) and maintained at this temperature for $2 \mathrm{~h}$ (from Bailly et al. ${ }^{[25]}$ ).

$\mathrm{MgCO}_{3}$ : was obtained from commercial hydromagnesite $\mathrm{Mg}_{5}\left(\mathrm{CO}_{3}\right)_{4}(\mathrm{OH})_{2} \cdot 4\left(\mathrm{H}_{2} \mathrm{O}\right)(\mathrm{Merck}$, purum p.a.) calcined at $623 \mathrm{~K}\left(5 \mathrm{~K} \cdot \mathrm{min}^{-1}\right.$ ramp) during $2 \mathrm{~h}$ in an oven.

$\mathbf{M g}_{3}\left(\mathbf{P O}_{4}\right)_{2}$ : was obtained from $\mathrm{Mg}\left(\mathrm{NO}_{3}\right)_{2} \cdot 6 \mathrm{H}_{2} \mathrm{O}$ (Sigma-Aldrich, 99.99\%) solution (0.1 mol.L $\mathrm{L}^{-1}$ ) using phosphoric acid (Carlo Erba Reagent, Analytical Grade) solution (0.1 mol.L $\left.\mathrm{L}^{-1}\right)$ as source of phosphorous and ammonia (Carlo Erba Reagent, Analytical Grade) solution (20\%) as precipitating agent. $100 \mathrm{~mL}$ of the magnesium nitrate solution is first added dropwise to $100 \mathrm{~mL}$ of phosphoric acid solution. The ammonia solution is then added dropwise until the $\mathrm{pH}$ value reaches the value of 7 at $303 \mathrm{~K}$ (around $30 \mathrm{~mL}$ ). The obtained 
product is washed 5 times with double distilled water, then dried at $373 \mathrm{~K}$, and finally calcined $2 \mathrm{~h}$ at $673 \mathrm{~K}$ in an oven (from Hiroaki et al. ${ }^{[26]}$ ).

$\mathrm{MgC}_{2} \mathbf{O}_{4}$ : was obtained from a saturated $\mathrm{Mg}(\mathrm{OAc})_{2}$ (Merck, 99.5\%) solution using oxalic acid (Sigma-Aldrich 99\%) solution $\left(6 \mathrm{~mol} . \mathrm{L}^{-1}\right)$ as a precipitating agent. The solid is then dried $24 \mathrm{~h}$ at $363 \mathrm{~K}$, and finally calcined $2 \mathrm{~h}$ at $623 \mathrm{~K}$ in an oven (from Putanov et al. ${ }^{[27]}$ ).

Magnesium silicate: several types of magnesium silicates were used in this study:

- Magnesol® catasorb and Magnesol® polysorb were kindly provided by the Dallas group of America®. The first one contains $\mathrm{Cl}(<0.5 \%)$ and $\mathrm{Na}(<2 \%)$ impurities, the second one, sulfate $(<1.5 \%)$ impurities but they have the same specific surface area. Both have the same reactivity therefore the influence of these impurities on the catalysis can be neglected. Only the results for Magnesol@ catasorb will be displayed with the label "Mg silicate (com)".

Two other magnesium silicate samples were synthesized using sol gel and co-precipitation methods. The molar ratio $\mathrm{Mg} / \mathrm{Si}$ is chosen to be similar to the one of $\mathrm{Mg}$ silicate (com), i.e. 0.290 (Table 1b)

- Sol-gel magnesium silicate, labeled "Mg silicate (sg)", is obtained with a procedure adapted from Kalampounias et $a l^{[28]}$. It consists in a hydrolysis and polycondensation of tetraethyl orthosilicate (TEOS) (Sigma-Aldrich, 99.999\%) with magnesium nitrate $\left(\mathrm{Mg}\left(\mathrm{NO}_{3}\right)_{2} \cdot 6 \mathrm{H}_{2} \mathrm{O}\right)($ Sigma-Aldrich, $98 \%)$ and nitric acid $\left(\mathrm{HNO}_{3}, 2 \mathrm{~N}\right)$ (VWR AnalaR Normapur). Nitric acid was used to catalyze the TEOS hydrolysis, using a molar ratio $\frac{\mathrm{H}_{2} \mathrm{O}+\mathrm{HNO}_{3}}{\mathrm{TEOS}}=8$. After the addition of all reactants in a Teflon bottle, the solution was stirred for $1 \mathrm{~h}$ at room temperature to allow the hydrolysis and polycondensation reactions, up until the formation of a viscous gel. The gel was aged, stored in the sealed Teflon bottles and kept at $333 \mathrm{~K}$ for 3 days, then it was dried in three stages at $333 \mathrm{~K}, 363 \mathrm{~K}$ and $403 \mathrm{~K}$ for $20 \mathrm{~h}, 24 \mathrm{~h}$ and $40 \mathrm{~h}$, respectively and calcined by steps at 
$373 \mathrm{~K}, 673 \mathrm{~K}$ and $973 \mathrm{~K}$ for $1 \mathrm{~h}, 2 \mathrm{~h}$ and $5 \mathrm{~h}$, respectively. The temperature increase rate was $0.1 \mathrm{~K} \cdot \mathrm{min}^{-1}$ for all heating procedures. The $\mathrm{Mg} / \mathrm{Si}$ ratio for this silicate is 0.321 .

- Co-precipitated magnesium silicate, labeled "Mg silicate (cp)", was obtained through a method adapted from Ozgul et al ${ }^{[29]}$. A solution of magnesium $\left(50 \mathrm{~mL}, 0.5 \mathrm{~mol} . \mathrm{L}^{-1}\right.$, from $\mathrm{MgCl}_{2} \cdot 6 \mathrm{H}_{2} \mathrm{O}$, Sigma-Aldrich, $\geq 99 \%$ ) was added dropwise into $10 \mathrm{ml}$ of sodium silicate solution (10\% $\mathrm{NaOH}$ and $27 \% \mathrm{SiO}_{2}$ wt., Sigma-Aldrich, reagent grade). A white precipitate was formed immediately. After $1 \mathrm{~h}$, the precipitate was filtered, washed with $3 \times 200 \mathrm{~mL}$ of distilled water and dried overnight at $333 \mathrm{~K}$. X-ray fluorescence of the sample indicate that the $\mathrm{Cl}$ concentration in the solid is lower than $0.1 \%$ and lower than $1 \%$ for $\mathrm{Na}$. The $\mathrm{Mg} / \mathrm{Si}$ ratio for this silicate is 0.268 .

Montmorillonite: Hydrofluoric acid (HF, $40 \%$ w/w; Fluka), sodium acetate $\left(\mathrm{NaCOOCH}_{3}\right.$, 99\%; Fluka), magnesium acetate $\left(\mathrm{Mg}\left(\mathrm{COOCH}_{3}\right)_{2} 4 \mathrm{H}_{2} \mathrm{O}\right.$, 99\%; Fluka), boehmite $\left(\mathrm{Al}_{2} \mathrm{O}_{3}\right.$, 75278\%, Pural SB1; Condea), and silica $\left(\mathrm{SiO}_{2}, 99.5 \%\right.$, Aerosil 130; Degussa) were used to prepare a hydrogel with the following chemical composition $1 \mathrm{SiO}_{2}: 0.15 \cdot \mathrm{Al}_{2} \mathrm{O}_{3}: 0.2 \cdot \mathrm{MgO}$ : $0.1 \cdot \mathrm{Na}_{2} \mathrm{O}: 0.05 \cdot \mathrm{HF}: 96 \cdot \mathrm{H}_{2} \mathrm{O}$. The hydrogel was matured during $4 \mathrm{~h}$ at room temperature, introduced into a PTFE-lined stainless steel autoclave and then heated at $473 \mathrm{~K}$ for $96 \mathrm{~h}$. Autoclave was then cooled to room temperature. Montmorillonite was recovered by filtration, washed thoroughly with distilled water and dried at $333 \mathrm{~K}$ for $12 \mathrm{~h}$. The ideal formula per half unit cell is $\mathrm{Na}_{0.4}\left[\mathrm{Si}_{4} \mathrm{Al}_{1.6} \mathrm{Mg}_{0.4} \mathrm{O}_{10}(\mathrm{OH}, \mathrm{F})_{2}\right]$ with a theoretical octahedral substitution rate (i.e the number of $\mathrm{Mg}^{2+}$ to $\mathrm{Al}^{3+}$ substitution per half-cell) of 0.4 , yielding a cationic exchange capacity of 0.764 meq. $\mathrm{g}^{-1}$. (from Jaber et al $\left.{ }^{[30]}\right)$.

2.2. Characterizations of the catalysts

- BET analysis: $\mathrm{N}_{2}$ adsorption-desorption isotherms were obtained at $77 \mathrm{~K}$ on a Micromeritics ASAP 2020 instrument. Prior to measurement, the samples (40 mg) 
were degassed under vacuum for 3 hours at $\mathrm{T}=573 \mathrm{~K}$ except for solids which could be deteriorated by the high temperature pretreatments, such as $\mathrm{Mg}(\mathrm{OH})_{2}$, pretreated at $393 \mathrm{~K}$, and magnesium silicate, pretreated at $523 \mathrm{~K}$. The Brunauer-Emmett-Teller (BET) surface areas were calculated from the BET equation for a relative pressure $\left(\mathrm{P} / \mathrm{P}_{0}\right)$ range between 0.05 and 0.25 .

- XRD: data were recorded on a diffractometer (D8 Bruker) with $\mathrm{Cu}-\mathrm{K} \alpha$ radiation (1.5418 $\AA ; 30 \mathrm{kV}$ and $30 \mathrm{~mA}$ ) and a Ni filter from $2 \theta$ of $10.0^{\circ}$ to $70.0^{\circ}$ (step size $\left.0.02^{\circ}\right)$. Crystalline phase identification was based on comparison with standard powder XRD files published by the International Center for Diffraction Data (ICDD).

- X-ray fluorescence: $\mathrm{The} \mathrm{Mg} / \mathrm{Si}$ ratios of the materials were determined using a SPECTRO XEPOS spectrometer equipped with a 50-Watt end-window X-ray tube to excite the samples. The detection system consists of a $10 \mathrm{~mm}^{2} \mathrm{Si}$-drift detector (SDD) with Peltier cooling and a spectral resolution of less than $155 \mathrm{eV}$ at $\mathrm{Mn} \mathrm{K \alpha}$ is achieved. Measurements were conducted in a He gas atmosphere.

- XPS analyses were performed using a PHOIBOS 100 X-ray photoelectron spectrometer from SPECS GmbH (Berlin, Germany) with a monochromated Al Ka Xray source $(\mathrm{h} v=1486.6 \mathrm{eV})$ operating at $\mathrm{P}=1.10^{-10}$ Torr or less. Spectra were carried out with a $50 \mathrm{eV}$ pass energy for the survey scan and $10 \mathrm{eV}$ pass energy for the $\mathrm{C} 1 \mathrm{~s}$, $\mathrm{O} 1 \mathrm{~s}, \mathrm{Si} 2 \mathrm{p}$, and $\mathrm{Mg} 2 \mathrm{p}$ regions. Auger peaks were recorded during XPS data acquisition and the Auger parameters were then calculated with respects to the Kinetic Energy of the X-ray source. Element peak intensities were corrected by Scofield factors. The spectra were fitted using Casa XPS v.2.3.15 Software (Casa Software Ltd.) and applying a Gaussian/Lorentzian ratio G/L equal to 70/30.

- Scanning Electron Microscopy with Field Emission Gun (SEM-FEG): SEM images were recorded with a Hitachi SU-70 field emission gun scanning electron microscope. The samples were fixed on an alumina SEM support with a carbon 
adhesive tape and were observed without metallization. An in-lens secondary electron detector (SE-Upper) was used to characterize our samples. The accelerating voltage was $1 \mathrm{kV}$, and the working distance was around $4 \mathrm{~mm}$.

- ${ }^{29}$ Si MAS NMR spectra were recorded with a Bruker Avance500 spectrometer at 99.4 $\mathrm{MHz}$ in $7 \mathrm{~mm}$ zirconia rotors. The chemical shifts of silicon were measured by reference to tetramethylsilane (TMS). ${ }^{29} \mathrm{Si}$ DPMAS NMR spectra were obtained at 7 $\mathrm{kHz}$ spinning speed, $3 \mu$ s excitation pulse and $10 \mathrm{~s}$ recycle delay. 3-(trimethylsilyl)-1propanosulfonic sodium salt was used for setting the Hartmann-Hahn conditions in ${ }^{29} \mathrm{Si}$ CPMAS NMR experiments. The proton $\pi / 2$ pulse duration, the contact time and recycle delay were $3.1 \mu \mathrm{s}, 5 \mathrm{~ms}$ and $5 \mathrm{~s}$, respectively. ${ }^{25} \mathrm{Mg}$ NMR spectra were performed with a Bruker Avance 700 spectrometer at $42.8 \mathrm{MHz}$ and with a $5 \mathrm{~mm}$ static probe.

- $\quad$ For WURST-QCPMG sequence ${ }^{[31]}$, WURST-80 pulse shapes was used with a $45 \mu$ s WURST pulse length, a sweep width of $500 \mathrm{kHz}$ and a RF power of $9.5 \mathrm{kHz}$. The echo delay was set at $0.5 \mathrm{~ms}$ and 30 echoes were collected. The spikelet spectrum was obtained by direct Fourier transform of the echo-train. The reconstructed spectrum was produced by fourier transform of sum of the individual echoes. Chemical shifts of magnesium was measured by reference to $\mathrm{MgCl}_{2}(\delta=0 \mathrm{ppm})$. The simulation of the NMR spectra were performed using the DMFit program. ${ }^{[32]}$

- DRIFT spectroscopy, Diffuse Reflectance Infrared Fourier Transform Spectroscopy (DRIFTS) was performed using a VECTOR 22 Bruker spectrometer with a DRIFTS cell (collector from Spectratech). The sample compartment of the cell was filled with the as-prepared sample ( 20 mg), which was first heated in situ under Ar flow (20 $\left.\mathrm{cm}^{3} \cdot \mathrm{min}^{-1}\right)$ up to $413 \mathrm{~K}\left(5 \mathrm{~K} \cdot \mathrm{min}^{-1}\right)$ for $1 \mathrm{~h}$. A first spectrum was taken at this temperature. The sample was then pretreated to $623 \mathrm{~K}\left(5 \mathrm{~K} \cdot \mathrm{min}^{-1}\right)$ for $1 \mathrm{~h}$ and then 
cooled down under Ar to $413 \mathrm{~K}$. The second spectrum was taken after this pretreatment. All spectra are recorded in situ and were converted into Kubelka-Munk units after subtraction of the spectrum recorded on the dehydrated $\mathrm{KBr}$ sample (Fluka, purity $>99.5 \%$ )

\section{3. $\mathrm{MBOH}$ conversion and transesterification in gas phase}

$\mathrm{MBOH}$ conversion and transesterification were processed in an automated microreactor. For each experiment, $40 \mathrm{mg}$ of catalyst were deposited on porous glass, in the center of a $10 \mathrm{~mm}$-i.d. $\mathrm{U}$ quartz tube and pretreated at $623 \mathrm{~K}$ during 2 hours (for $\mathrm{MBOH}$ ) or at $393 \mathrm{~K}$ (for transesterification) under nitrogen (Air Liquide 99.99\%), except for magnesium carbonate to avoid decomposition (573 K for $\mathrm{MBOH}, 393 \mathrm{~K}$ for transesterification). The reaction temperature for both reactions was controlled within $\pm 0.1 \mathrm{~K}$ by a thermocouple located near the catalyst. The specificities for the two reaction conditions were:

- For MBOH conversion: the reactant feed that was composed of $\mathrm{MBOH}$ diluted by bubbling nitrogen $\left(50 \mathrm{~mL} \cdot \mathrm{min}^{-1}\right.$ through a Brooks gas mass flow controller $)$ in liquid $\mathrm{MBOH}$ (Fluka, 99.9\%) maintained at $293 \mathrm{~K}$. Diluted MBOH flow (partial pressure of $1.73 \mathrm{kPa}$ ) was then allowed to pass through the catalyst. Reaction temperatures were 393 and $433 \mathrm{~K}$.

- For the transesterification: methanol (Sigma Aldrich anhydrous 99.8\%) and ethyl acetate (Sigma Aldrich anhydrous 99.8\%) were premixed and introduced with a molar ratio of 24.25 . The liquid flow rate was $0.225 \mathrm{~g} \cdot \mathrm{h}^{-1}$ for the mixture by means of a liquid mass flow meter (Bronkhorst liquid mass flow controller), mixed and vaporized in a gas flow of nitrogen (Air Liquide 99.99\%), introduced through a Bronkhorst gas mass flow controller. Flow rate for nitrogen was kept at $45 \mathrm{~cm}^{3} \cdot \mathrm{min}^{-1}$. Therefore, the partial pressure of methanol in the reactor is 55.8 $\mathrm{Pa}$ and the partial pressure of ethyl 
acetate is $2.42 \mathrm{~Pa}$. The first analysis was carried out $600 \mathrm{~s}$ after the introduction of the mixture on the sample. Reaction temperature was $393 \mathrm{~K}$.

- $\quad$ Reaction products were analyzed:

○ every 540 s using a Perichrom PR2100 equipped with a tetracyanoethylene pentaerythritol on chromosorb $\mathrm{P}$ column ( $\mathrm{MBOH}$ conversion)

o every 486 s using a Varian chromatograph equipped with a FID detector and a CP WAX 57 CB column (transesterification).

In both cases the conversion $\tau$ is given by Equation 1 , with $\mathrm{P}_{\mathrm{r}}^{\circ}$ and $\mathrm{P}_{\mathrm{r}}$ the limiting reactant partial pressure ( $\mathrm{MBOH}$ and ethyl acetate respectively) determined before reaction and after reaction.

$$
\tau=\frac{\mathrm{P}_{\mathrm{r}}^{\circ}-\mathrm{P}_{\mathrm{r}}}{\mathrm{P}_{\mathrm{r}}^{\circ}}
$$

However, for very low activity, the conversion is evaluated from the products partial pressure. Carbon balance is systematically checked and is always determined at values over $95 \%$ except for $\mathrm{Mg}$ silicate sg (10\% deficit in $\mathrm{MBOH}$ conversion)

Ethanol and methyl acetate are the only products detected for the transesterification, thus catalytic data are expressed in terms of conversion only.

For MBOH, propanone and ethyne as well as 3-methyl-but-3-en-1-yne (Mbyne) were detected. The selectivity for a route (acidic or basic) is given by Equation 2:

$$
S_{i}=\frac{P_{i}}{\sum \alpha_{i} P_{i}}
$$

where $P_{i}$ is the pressure of ethyne for the basic route and Mbyne for the acidic route $\alpha_{i}$ $=1$ for Mbyne and $\alpha_{i}=1 / 2$ for propanone and ethyne

For all conversions, the normalized conversion per surface area is obtained by dividing the conversion (expressed in \%o) with the specific surface area (in $\mathrm{m}^{2} \cdot \mathrm{g}^{-1}$ ). 


\subsection{Transesterification in liquid phase}

\subsubsection{General procedure}

$40 \mathrm{mg}$ of the catalyst were introduced in a Schlenk flask. Vacuum was then performed in the Schlenk flask through a vacuum manifold $\left(10^{-3}\right.$ torr $)$, during $30 \mathrm{~min}$ and then heated in an oil bath at $343 \mathrm{~K}$. With this kind of configuration, the temperature of the liquid phase was 333 K. One hour later, nitrogen (Air liquide 99.99\%) was introduced into the Schlenk (1 bar) and then $10 \mathrm{~mL}$ of methanol (Sigma Aldrich anhydrous 99.8\%) as well as $1 \mathrm{~mL}$ of 1,4 dioxane (Sigma Aldrich anhydrous 99.8\%), as standard reference, were introduced through needles into the Schlenk. The introduction of $1 \mathrm{~mL}$ of ethyl acetate (Sigma Aldrich anhydrous $99.8 \%)$ determines the initial time of the reaction $(\mathrm{t}=0)$. Like in the gas phase, the molar ratio between the reactants was kept at 24.25 .

\subsubsection{Determination of the conversion}

The ratios ethyl acetate/dioxane, methyl actetate/dioxane, ethanol/dioxane, and methanol/dioxane were checked at the beginning $(t=0 h)$ and after 5 hours of reaction $(t=5$ h) by gas chromatography. To perform these analyses few drops of reaction mixture were drawn from the Schlenk and diluted in $2 \mathrm{~mL}$ of $\mathrm{n}$-butanol (Sigma Aldrich, ACS reagent). The only detected products were methyl acetate and ethanol; therefore the conversion was calculated through equation 3:

$$
\tau=\frac{\left(\frac{\text { AcOEt }}{\text { Dioxane }}\right)_{t=0}-\left(\frac{\text { AcOEt }}{\text { Dioxane }}\right)_{t=5 h}}{\left(\frac{\text { AcOEt }}{\text { Dioxane }}\right)_{t=0}}
$$

Eq. 3: Calculation of the conversion in liquid phase

\subsubsection{Homogeneous catalysis}

The potential occurrence of homogeneous catalysis by dissolution of the material in the reaction mixture was tested by removing the solid catalyst by means of centrifugation 
followed by a filtration of the reaction mixture. The filtrate was again used in the same reacting conditions overnight. If the conversion does not evolve, it is concluded that the catalytic process is purely heterogeneous.

\section{Results}

3.1. Specific surface areas of the solids

Specific surface areas vary between 33 and $447 \mathrm{~m}^{2} \cdot \mathrm{g}^{-1}$ (Tables 1a and 1b). One should remain aware that the catalytic conversion for various solids has to be compared carefully, the higher specific surface areas leading mechanically to larger conversions for experiments using identical mass of catalyst.

\subsection{Reactivity towards $\mathrm{MBOH}$}

$\mathrm{MBOH}$ molecule decomposes on solids following different routes depending on the presence of acid or basic sites. ${ }^{[24]}$ Scheme 1 shows the two main routes followed on a large majority of solids: the acidic one leading to 3-methyl-but-3-en-1-yne (Mbyne) and the basic one producing propanone and ethyne.

Figure 1 gives the results obtained at reaction temperatures of $393 \mathrm{~K}$ (Figure 1a) and 433K (Figure 1b) as well as the conversion normalized per surface unit, for conversions low enough to make this parameter meaningful $(<50 \%)$.

Three main groups of materials can be identified on the basis of their selectivity, thus the routes they follow according to Scheme 1:

i. Materials following basic route

As shown in Figure 1a, MBOH is converted at $393 \mathrm{~K}$ into propanone and ethyne, the specific route of basic sites, on $\mathrm{MgO}, \mathrm{MgCO}_{3}, \mathrm{Mg}(\mathrm{OH})_{2}$ and $\mathrm{MgC}_{2} \mathrm{O}_{4}$ confirming the wellknown basic character of those solids. For all tested solids, a small deactivation of the catalyst 
is noticed (around $20 \%$ after 1 hour), which can be associated with the polymerization of the propanone on basic sites. ${ }^{[24]}$ On the basis of conversion, a basicity rank can be given as :

$$
\mathrm{MgO}>\mathrm{MgCO}_{3}>>\mathrm{Mg}(\mathrm{OH})_{2}>\mathrm{MgC}_{2} \mathrm{O}_{4}
$$

This order of basic reactivity could be discussed on the basis of protonic affinity of the anion (related to its ability to bond to a proton ${ }^{[33]}$ ) which is given in Table 1a. A rough correlation can be observed, even when the conversion is expressed per surface unit. Indeed, the two more active catalysts $\left(\mathrm{MgO}\right.$ and $\left.\mathrm{MgCO}_{3}\right)$ involve the anions exhibiting the higher proton affinity. Nevertheless a strict correlation is not and cannot be obtained as $\mathrm{MBOH}$ conversion needs the deprotonation of the alcohol thus the stabilization of the alcoholate counterpart which is not taken into account in the proton affinity data. ${ }^{[34]}$

\section{ii. Materials following acidic route}

Among all the tested materials, magnesium phosphate and montmorillonite converted $\mathrm{MBOH}$ following the acidic route, thus leading to Mbyne production (Figure 1b). According to the literature, the surface of magnesium phosphate is able to adsorb large quantity of acid (phenol) and base (cyclohexylamine). ${ }^{[35]}$ Furthermore, Aramendía et al. showed that hexan-2ol is converted through acidic (towards alkene) and basic (towards ketone) routes in different proportion depending on the preparation of the solid. ${ }^{[36]}$ Our preparation method has therefore favored the acid sites. Besides, a quick deactivation of the catalyst is observed $(50 \%$ less reactivity after 11 minutes on stream). This result may be related to the polymerization of the alkenes on the surface.

In the case of montmorillonite, the acidic reactivity is in line with the results recently published by Novikova et al. ${ }^{[37]}$ on the $\mathrm{MBOH}$ conversion on various natural clay minerals. In this recent study, formation of propanone and ethyne is also observed whereas on our samples pure acidic reactivity is obtained. This discrepancy may be explained by the use of 
natural clay minerals in the work of Novikova et al. containing a lot of impurities such as quartz, iron oxide, calcium carbonate while we used a pure synthetic montmorillonite.

iii. Materials following both acidic and basic route.

Magnesium silicates have a very interesting reactivity since products of acid route (Mbyne) and those of basic route (propanone and ethyne) are detected together. However, the ratio of the products resulting from acidic and basic routes is not the same for all the silicates. For similar conversion, the co-precipitated silicate gives $78 \%$ selectivity on the basic route compared to $19 \%$ for the sol-gel. Moreover, the commercial magnesium silicate is slightly more active than the co-precipitated one but quite similar in terms of selectivity.

\subsection{Transesterification in liquid and gas phase}

All the materials were tested in the transesterification of ethyl acetate by methanol processed both in liquid and gas phases. In each case the same molar reactant ratio was used (methanol/ethyl acetate $=24.25$ ). The reaction temperature was fixed to $333 \mathrm{~K}$ for the liquid phase and $393 \mathrm{~K}$ for the gas phase in all the experiments. In gas phase, little to no deactivation is observed. The results are given (Figure 2) at initial time on stream (3 minutes) in gas phase and after 5 hours of reaction for liquid phase.

For the liquid phase experiments, the potential homogeneous contribution has been checked for all the materials, as indicated in the experimental part and a notable progress of the conversion have been found after filtration of the reaction mixture for the magnesium carbonate. The results obtained in liquid phase for this material have thus not be considered. For all the other catalysts, it can be assessed that the catalytic behavior is strictly heterogeneous. 
It appears immediately from Figure 2 that the three groups of materials differentiated by $\mathrm{MBOH}$ conversion also give very different catalytic performances in transesterification reaction:

i- The solids that only follow the acidic route in $\mathrm{MBOH}$ conversion (montmorillonite and magnesium phosphate) are completely inactive for this transesterification reaction, both in liquid and in gas phases. Phosphate is often used for transesterification with sodium or potassium as a counter-ion, which are leached in the reaction mixture. ${ }^{[11,12]}$ When the counterion used is magnesium, the solubility of the solid is much smaller. Therefore, most of the catalysis carried out by these solids in those studies is eventually mostly done homogeneously by leached chemical species.

Wibowo et al ${ }^{[18]}$ show that a lithium exchanged montmorillonite exhibits a good activity in the reaction between methyl laurate and glycerol. It can also be found that the exchange of montmorillonite with barium improves its reactivity. ${ }^{[38]}$ In our case, the poor activity of montmorillonite can be related to the acid-base properties induced by the nature of the interlayer cations that may modify the reactivity of the catalyst, as shown in section 3.2.ii. The reagents were also not the same.

ii- In the case of purely basic catalyst in the $\mathrm{MBOH}$ conversion, a clear distinction can be established between magnesium carbonate and magnesium oxide and the other basic catalysts. These two materials that exhibit a very high basic reactivity in $\mathrm{MBOH}$ conversion give also full conversion in gas phase transesterification while magnesium hydroxide and oxalate are almost inactive in these conditions.

In liquid phase, they show moderate activity (from $18 \%$ to $8 \%$ ), the largest conversion is obtained for $\mathrm{MgO}$ used without pretreatment. However, $\mathrm{Mg}(\mathrm{OH})_{2}$, with a much smaller specific surface area, is showing a conversion normalized per surface area (\%o.g.m $\left.{ }^{-2}\right)$ almost 
three times higher. Even if $\mathrm{MgO}$ is pretreated to remove hydroxyls and carbonates, as we did in a previous publication ${ }^{[10]}$, the activity per surface area of brucite is still larger.

iii- The magnesium silicates, that convert $\mathrm{MBOH}$ following both the basic and the acidic routes show moderate activity in gas phase transesterification, around $20 \%$ conversion but give quite interesting reactivity in liquid phase even when one considers that these solids present a very large specific surface. More precisely, it can be observed that the two more efficient are co-precipitated and commercial silicates (with respectively $38 \%$ or $0.9 \%$ o.g.m ${ }^{-2}$ and $29 \%$ or $0.65 \%$ o.g. $\mathrm{m}^{-2}$ conversion) while a much lower activity is observed for the sol-gel silicate $\left(11 \%\right.$ or $0.37 \%$ o.g.m $\left.{ }^{-2}\right)$. Thus, among these three catalysts, the two more active in the liquid phase are those exhibiting the best basic selectivity in $\mathrm{MBOH}$ conversion, while, the sol-gel magnesium silicate that gives $81 \%$ selectivity in Mbyne is much less active in liquid phase transesterification.

\subsection{Structure of the magnesium silicates}

The three magnesium silicates (com, sg, cp) have distinct acid-base properties and different reactivities in liquid phase transesterification despite similar compositions and specific surfaces. To explain those differences, various characterizations of the catalyst were performed.

\subsubsection{X-ray spectroscopies}

The X-ray diffractrogram (Figure 3) of Mg silicates (com) shows some broad peaks at $2 \theta=35,60$ and $72^{\circ}$. Those peaks are also present on the Mg silicate (cp), even if they are less pronounced. Literature ascribed those broad peaks together with an additional one at $2 \theta=20^{\circ}$, which in our case disappears in the large band of amorphous silica. ${ }^{[39-41]}$, to a structure named "Magnesium Silicate Hydrate" (MSH). This kind of phase is usually obtained for Mg/Si ratios higher than 0.5 and consist in magnesium surrounded by an octahedron formed by oxygen, sandwiched between silicate layers. The exact structure of those layers is not defined in this study, but the deficiency of silicate tetrahedrons compared to the magnesium one is well 
known for MSH. ${ }^{[41]}$ A simple putative representation of the $\mathrm{Si}-\mathrm{O}-\mathrm{Mg}$ skeleton is given in Scheme 2. On the opposite, only the silica broad band is visible on the Mg silicate (sg) diffractogram (Figure 3).

Table $1 \mathrm{~b}$ gathered the magnesium and silicon content of the surface (through XPS) and within the catalyst (through X-ray Fluorescence). It can be seen from these data that solgel magnesium silicate presents a homogenous repartition of the magnesium with a $\mathrm{Mg} / \mathrm{Si}$ ratio around 0.33 similar to the one found in the bulk, whereas commercial and coprecipitated $\mathrm{Mg}$ silicates show enriched magnesium content in the surface compared to the one observed on the whole solid.

Therefore, the MSH structures observed by XRD in the commercial and coprecipitated catalysts are more likely to be located on the surface, as only those regions have a $\mathrm{Mg} / \mathrm{Si}$ ratio high enough. In the case of the sol-gel sample no crystallized phase was detected by XRD and the material seems to be more homogeneous.

\subsubsection{Scanning electron microscopy}

The images in Figures S1, S2 and S3 confirm the distinction observed in the X-ray techniques. Indeed, Mg silicate ( $\mathrm{sg}$ ) surface is smooth whereas the ones for the (cp) and the (com) are very corrugated. It is in line with a very homogeneous composition of the sol-gel particle and the presence of poorly crystalline phases over the surface of Mg silicate (com) and (cp). Chiang and co-workers ${ }^{[42]}$ as well as Tonelli and co-workers ${ }^{[43]}$ observe the same kind of structure. According to Chiang et al., the MSH forms globules of a few nanometers (the mean value of their size being $3 \mathrm{~nm}$ ) which corresponds to what is shown for $\mathrm{Mg}$ silicate (com) and $\mathrm{Mg}$ silicate (cp).

\subsection{3. ${ }^{29} \mathrm{Si}$ and ${ }^{25} \mathrm{Mg}$ NMR study on the magnesium silicates}

To go further, $\left\{{ }^{1} \mathrm{H}-{ }^{29} \mathrm{Si}\right\}$ Direct Polarization (DP), in figure 4 and Cross Polarization (CP) Magic Angle Spinning (MAS)-NMR experiments were performed (Figure S4). CP and DP spectra are similar for the three silicates, therefore, only the DP one will be discussed. As 
reported in the literature, ${ }^{[41,43-48]}$ the ${ }^{29} \mathrm{Si}$ MAS NMR spectra (Figures 4 and S4) can be decomposed in two ranges. The resonances from $-112 \mathrm{ppm}$ to $-99 \mathrm{ppm}$ and -98 to $-70 \mathrm{ppm}$ are attributed respectively to silicates without direct connection to magnesium (labeled SiOSi), and silicate with at least one oxygen connected to magnesium (labeled SiOMg). In addition to this first classification, the signals recorded by ${ }^{29} \mathrm{Si}$ MAS NMR experiments can be classified into $\mathrm{Q}^{\mathrm{n}}$ species (where $\mathrm{Q}$ represents the $\mathrm{Si}$ atom which is bonded to four oxygen atoms and $\mathrm{n}$ is the number of Si neighbors). ${ }^{[49]}$ For the SiOSi, the two broad peaks centered to around -110 ppm and -101 ppm are assigned to $\mathrm{Q}_{\mathrm{SiOSi}}^{3}$ silica species $\left(\mathrm{Si}(\mathrm{OSi})_{3}(\mathrm{OH})\right.$ ) and completely condensed species $\mathrm{Q}_{\text {SiOSi }}^{4}\left(\mathrm{Si}(\mathrm{OSi})_{4}\right)$, respectively. ${ }^{[43,46,48,49]}$ For the $\mathrm{SiOMg}$ silicates, due to structural deformations, the decomposition is more difficult because each type of $\mathrm{Q}^{\mathrm{n}}$ may consist of different contributions. ${ }^{[41,43,45-47,50]}$ According to the literature ${ }^{[41,43,46,47]}$, it is possible to define three zones for the $\mathrm{SiOMg}$ phase: from -89 to $-98 \mathrm{ppm}$ for $\mathrm{Q}_{\text {SiOMg }}^{3}$ species (i.e. $\mathrm{Si}(\mathrm{OSi})_{3}(\mathrm{OMg})$ ), from -82 to $-88 \mathrm{ppm}$ for $\mathrm{Q}_{\text {SiOMg }}^{2}$ species (i.e. $\mathrm{Si}(\mathrm{OSi})_{2}(\mathrm{OMg})(\mathrm{OH})$ ) and from -70 to -81 ppm for $\mathrm{Q}_{\mathrm{SiOMg}}^{1}$ species (i.e. $\left.\mathrm{Si}(\mathrm{OSi})(\mathrm{OMg})(\mathrm{OH})_{2}\right) . \quad{ }^{29} \mathrm{Si}$ spectra of $\mathrm{Mg}$ silicates (com) and (cp) (Figures 4.A-B and S4.A-B), show clearly overlapping signals at around -94 ppm, which are ascribed to different $\mathrm{Q}_{\text {SiOMg }}^{3}$ sites. Moreover, one peak was identified at $-85 \mathrm{ppm}$, due to $\mathrm{Q}_{\text {Siomg }}^{2}$ site $^{[45,46,48,50]}$ and two peaks were found at around $-80 \mathrm{ppm}$ which can be attributed to different $\mathrm{Q}_{\text {Siomg }}^{1}$ species. ${ }^{43}$ The $\mathrm{Mg}$ silicate (sg) sample (Figures 4.C and S4.C) appears to have the same contributions but with two new signals at $-88 \mathrm{ppm}$ $\left(Q_{\text {SiOMg }}^{2}\right)$ and $-74.5 \mathrm{ppm}\left(\mathrm{Q}_{\text {SiOMg }}^{1}\right)$.

Therefore, ${ }^{29} \mathrm{Si}$ MAS NMR spectra confirm the presence of silicates connected $(\mathrm{SiOMg})$ and not connected (SiOSi) to magnesium in all samples. The spectra of $\mathrm{Mg}$ silicate (com) and Mg silicate (cp) are very similar (Figure 4.A-B), they show that the proportion of silicates bond to magnesium phase is large. These silicates are essentially constituted by $\mathrm{Q}^{3}$ species $\left.\mathrm{Si}(\mathrm{OSi})_{3}(\mathrm{OMg})\right)$, branching silicate chain sites with the structural deformation 
expected for a MSH phase ${ }^{[41,43,46,47]}$ like the one depicted by Scheme 2. In the Mg silicate (sg) sample (Figure 4.C) the silicates only connected to other silicates are more important and the contribution of silicates connected to magnesium is larger, with a proportion of $Q^{2}$ and $Q^{1}$ species more important that reflects a very disordered structure.

Due to the low natural abundance $(10 \%)$, quadrupolar nature $(I=5 / 2)$ and low resonance frequency of magnesium, ${ }^{25} \mathrm{Mg}$ NMR spectra are more difficult to record and explain than ${ }^{29} \mathrm{Si}$ spectra. ${ }^{[51,52]}$ The spectra of the three samples show only one peak (Figure 5). The broadening of the signal is induced by quadrupolar interaction and the slightly asymmetrical shape of the center band corresponds to a distribution in quadrupolar coupling parameters. ${ }^{[53]}$ The lineshape simulation with Czjzek model for Mg silicate (com) gives an isotropic chemical shift, $\delta_{\text {iso }}=26 \mathrm{ppm}$ and a quadrupolar coupling constant, $\mathrm{C}_{\mathrm{Q}}=3.5 \mathrm{MHz}$, in good agreement with Nied et al. ${ }^{[46]}$ values. The parameter values of Mg silicate (cp) are very close to those of $\mathrm{Mg}$ silicate (com), $\delta_{\text {iso }}=26 \mathrm{ppm}$ and $\mathrm{C}_{\mathrm{Q}}=3.8 \mathrm{MHz}$. But the fitted parameters for $\mathrm{Mg}$ silicate $(\mathrm{sg})$ sample are significantly different, $\delta_{\text {iso }}=31 \mathrm{ppm}$ and $\mathrm{C}_{\mathrm{Q}}=6.9$ MHz.

The large increase of quadrupolar coupling constant of Mg silicate (sg) (twice as large that $\mathrm{Mg}$ silicate (com) and $\mathrm{Mg}$ silicate (cp)) suggests large distortion of the local coordination. ${ }^{[51,52]}$ This is in line with the formation of MSH phase only for Mg silicate (cp) and $\mathrm{Mg}$ silicate (com) in which the magnesium occupies octahedral positions, giving mainly $\mathrm{Q}^{3}$ species $\mathrm{Si}(\mathrm{OSi})_{3}(\mathrm{OMg})$ in ${ }^{29} \mathrm{Si}$ spectra, as presented in Scheme 2, therefore with a small quadrupolar coupling.

\subsubsection{DRIFT characterization}

Figures S5 and 6 show the DRIFT spectra of the silicates, both taken at $413 \mathrm{~K}$, before and after a $623 \mathrm{~K}$ pretreatment, respectively. After pretreatment, the contribution of adsorbed molecular water $\left(1630 \mathrm{~cm}^{-1}\right)^{[46]}$ disappeared but a broad absorbance in the zone associated 
with O-H elongations (3000-3800 $\mathrm{cm}^{-1}$ ) remains for all the samples, similar to the contribution usually found on pure silica. However, a sharp band emerges at $3737 \mathrm{~cm}^{-1}$ for all the samples and a second one at $3672 \mathrm{~cm}^{-1}$ for the $\mathrm{Mg}$ silicate (com) and, in a lower extend, for the Mg silicate (cp). Those two bands can also be seen on the samples pretreated only at $413 \mathrm{~K}$ but were more difficult to recognize because of the presence of residual molecular water adsorbed in these conditions. The contribution at $3672 \mathrm{~cm}^{-1}$ was previously assigned to $\mathrm{OH}$ stretching in the talc structure, ${ }^{[54]}$ or to similar structures ${ }^{[46]}$ and is therefore compatible with the presence of MSH structure. The band located at $3737 \mathrm{~cm}^{-1}$ is in the range observed for silanols over silica ${ }^{[43]}$ and should be attributed to $\mathrm{OH}$ stretching of silanols species that can be in close proximity to magnesium cations. A band at $1720 \mathrm{~cm}^{-1}$ appears then, that is attributed to $\mathrm{Si}-\mathrm{OH}$ vibrations. ${ }^{[43]}$

3.4.5. Conclusion on the characterization of the magnesium silicates

These characterizations enlighten that the three magnesium silicates used in this work, exhibit different surfaces as shown by the characterization results obtained. From XPS results, it is clearly shown that Magnesol® and $\mathrm{Mg}$ silicate (cp) surfaces are enriched in magnesium while $\mathrm{Mg}$ silicate ( $\mathrm{sg}$ ) exhibit on its surface the same $\mathrm{Mg} / \mathrm{Si}$ ratio as in the bulk. XRD, NMR and DRIFTS give coherent data showing the formation on $\mathrm{Mg}$ silicate (cp) and on $\mathrm{Mg}$ silicate (com) of a magnesium silicate hydrate (MSH) phase. Data are in agreement with the possibility of the presence at their surface of talc sheet with defective silicate layers.

\section{Discussion}

4.1. Differences between liquid and gas phase transesterification

Firstly, one can observe that the most active catalysts for gas phase transesterification (magnesium oxide and magnesium carbonate) are not the same as the ones for the liquid phase transesterification (magnesium silicate (cp) and also $\mathrm{Mg}(\mathrm{OH})_{2}$, the latter having a very large conversion normalized per surface unit). This result is also found for $\mathrm{Mg}$ silicate having 
the same composition: $\mathrm{Mg}$ silicate (sg) and $\mathrm{Mg}$ silicate (cp) have the same reactivity in gas phase, but the latter is much more active than the first one in liquid phase. This was already observed for the conversion on magnesium oxide as a catalyst ${ }^{[10]}$ and confirms the hypothesis of the occurrence of two different mechanisms in liquid and gas phases.

\subsection{Link between acid-base properties and conversion}

Some explanation for this difference of behavior in the two phases can be found by looking at the acid-base properties of the solids. The best reactivity in gas phase transesterification is obtained on purely basic (from $\mathrm{MBOH}$ conversion) materials and the level of activity in transesterification is well correlated to the level of activity obtained in MBOH conversion. The transesterification in gas phase therefore benefits from strong basic Brønsted sites found on $\mathrm{MgO}$ and on $\mathrm{MgCO}_{3}$. Hydroxides and oxalates are not basic enough to perform this transformation efficiently. Silicates, which associate basic and acidic sites, also convert methanol and ethyl acetate in gas phase at a moderate level but higher than purely acidic catalysts. Therefore, even if there is no fine correlation between the activity in gas phase transesterification and in model reactions of basicity, the strongest bases according to $\mathrm{MBOH}$ model reaction are the best catalysts. In a previous publication, ${ }^{[10]}$ we made the hypothesis that deprotonated ester could be a valid reaction intermediate in gas phase transesterification. The fact that weak bases are not really active in this reaction is still in line with this previous proposition.

On the other side, for the liquid phase, strong basicity is no more necessary and magnesium silicates that possess both sites able to convert $\mathrm{MBOH}$ into propanone and ethyne and into Mbyne are efficient catalysts. $\mathrm{Mg}(\mathrm{OH})_{2}$ is also a very reactive catalyst, despite its very low basicity. The Eley-Rideal mechanism proposed by Dossin et al, ${ }^{[55]}$ for the same reaction on $\mathrm{MgO}$, implies that methanol adsorption is the rate determining step. In that case, a 
correlation should be observed with the basic properties of the materials. It is not the case with the magnesium silicates as well as $\mathrm{Mg}(\mathrm{OH})_{2}$; it can then be presumed that another mechanism has to be proposed for this kind of solids.

\subsection{A bifunctional catalyst: Magnesium Silicate Hydrate and its reactivity}

From the results shown in Figure 1b, we can compare the selectivity of the $\mathrm{MBOH}$ conversion on the three magnesium silicates. The ratio of the conversion through the acidic way over the conversion through the basic route is 4.3 for the $\mathrm{Mg}$ silicate ( $\mathrm{sg}$ ), 0.4 for $\mathrm{Mg}$ silicate (com) and 0.3 for $\mathrm{Mg}$ silicate (cp). It is well known that magnesium silicate may possess both acidic and basic sites depending on the way of synthesis. Indeed, silanol groups over silica are mostly acidic, ionic oxygen ions in magnesium oxide are basic. ${ }^{[56]}$ The repartition of the silica tetrahedrons and the magnesium and their coverage with hydroxyl groups, carbonates or water will determine the exact acid-base nature of the surface. For instance, the variation of the acid base properties for the sol-gel magnesium silicate was reported by Kriesel and Tilley. ${ }^{[57]}$ We find here that the samples exhibiting the MSH phase (com) and (cp) are more selective in $\mathrm{MBOH}$ conversion towards the basic way than the solgel sample. The MSH phase that was characterized in the part 3.4 is usually described as short talc sheets with defective silicon tetrahedra layers. These defects, localized at the surface of the material may give accessibility to the octahedral magnesium layer, that may generate surface basicity directly or as hydroxyl or carbonate groups. In addition, XRD analysis on the spent catalyst (result not shown) is strictly identical to the one obtained on the fresh sample (Figure 3) showing that this phase is stable during the reaction.

This heterogeneous catalyst is thus bifunctional and offers on the same surface acidic and basic active sites. Acids and bases known to catalyze transesterification in homogeneous catalysis can cooperate on an inorganic surface: for example, when the acidic catalysis 
activates the ester through the oxygen of the carbonyl bond, the basic catalysis often activate the alcohol through its deprotonation. Both combined improve the nucleophilic addition of the alcohol or of the alcoholate over the ester. Such a mechanism could occur on magnesium silicates exhibiting MSH that react with $\mathrm{MBOH}$ both along the acidic and the basic route. The sol-gel sample on which no MSH phase is more acidic than the two other silicates in $\mathrm{MBOH}$ conversion test that may explain its lowest activity in liquid phase transesterification.

\section{Conclusion}

The activity, in liquid and gas phases, of a series of magnesium-based materials with various acido-basic properties for the same transesterification reaction was studied and it was shown that the catalytic ranking differs between both conditions supporting the hypothesis of two different mechanisms, depending on the operating conditions.

The best catalysts for the reaction in gas phase are magnesium oxide and magnesium carbonate, which are the most active in a model reaction of basicity (conversion of $\mathrm{MBOH}$ ). Therefore, it seems that strong enough basic sites are needed to catalyze efficiently the reaction in gas phase. This is line with our former suggested mechanism for the gas phase transesterification, involving a deprotonated ester. On the other side, in liquid phase, weakly basic materials, as magnesium silicates or $\mathrm{Mg}(\mathrm{OH})_{2}$ show large conversions.

The highest conversions in liquid phase are found for co-precipitated magnesium silicate and the commercial catalyst Magnesol®. These two catalysts convert MBOH towards acidic and basic ways. ${ }^{29} \mathrm{Si}$ and ${ }^{25} \mathrm{Mg}$-NMR, IR, X-ray fluorescence and X-ray photoelectron spectroscopies, together with XRD show that those solids are covered with magnesium silicate hydrate (MSH) with covalently bound oxygen and oxygen solely linked to magnesium. This phase, well-known in the field of cement and concrete, could explain the 
peculiar reactivity of these bifunctional catalysts and has never been identified on magnesium silicates catalysts tested in transesterification reactions

The role of water has been investigated in a former study on $\mathrm{MgO}$ showing a maximum of activity in liquid phase for intermediate hydroxyl coverage. As the active MSH phase identified in the present study is highly hydroxylated, on-going studies concern the influence of the pretreatment of magnesium silicates before the reaction.

\section{Acknowledgments}

The authors acknowledge IMPC (Institut des Matériaux de Paris Centre, FR2482) and the C'Nano projects of the Region Ile-de-France, for SEM-FEG and Omicron XPS apparatus funding. Christophe Méthivier and Sandra Casale are deeply acknowledged for their important help in XPS calculations and SEM images, respectively. Furthermore, the cluster of excellence Matisse and China Scholarship Council (File No.201406140144) are thanked for Daou M. Master's degree grant and Lin L. PhD funding, respectively. The bars graphs for the conversions were created with the software R. The authors thank Maëlle Salmon for her help in making the graphs. 


\section{References}

$1 \quad$ M. R. Avhad and J. M. Marchetti, Catal. Rev., 2016, 58, 157-208.

2 D. M. Alonso, S. G. Wettstein and J. A. Dumesic, Green Chem., 2013, 15, 584.

3 T. Dossin, M. Reyniers and G. Marin, Appl. Catal. B Environ., 2006, 62, 35-45.

4 E. Leclercq, A. Finiels and C. Moreau, J. Am. Oil Chem. Soc., 2001, 78, 1161-1165.

5 H. Hattori, M. Shima and H. Kabasjima, Stud. Surf. Sci. Catal., 2000, 130D, 35073512.

6 J. I. Di Cosimo, V. K. Díez, C. Ferretti and C. R. Apesteguía, Catalysis, Royal Society of Chemistry, Cambridge, 2014, vol. 26.

7 F. S. H. Simanjuntak, S. R. Lim, B. S. Ahn, H. S. Kim and H. Lee, Appl. Catal. A Gen., 2014, 484, 33-38.

8 G. Busca, Ind. Eng. Chem. Res., 2009, 48, 6486-6511.

9 C. Xu, D. I. Enache, R. Lloyd, D. W. Knight, J. K. Bartley and G. J. Hutchings, Catal. Letters, 2010, 138, 1-7.

10 D. Cornu, H. Guesmi, G. Laugel, J.-M. Krafft and H. Lauron-Pernot, Phys. Chem. Chem. Phys., 2015, 17, 14168-76.

11 S. L. Britton, J. Q. Bond and T. W. Root, Energy \& Fuels, 2010, 24, 4095-4096.

12 S. T. Jiang, F. J. Zhang and L. J. Pan, Brazilian J. Chem. Eng., 2010, 27, 137-144.

13 D. M. Reinoso, D. E. Damiani and G. M. Tonetto, Appl. Catal. B Environ., 2014, 144, 308-316.

14 A. Zieba, A. Pacula and A. Drelinkiewicz, Energy \& Fuels, 2009, 24, 634-645.

15 L. E. Manzer, Appl. Catal. A Gen., 2004, 272, 249-256.

16 WO 2004007421 A1, 2004.

17 P. Arpino and G. Ourisson, Anal. Chem., 1971, 43, 1656-1657.

18 T. Y. Wibowo, A. Z. Abdullah and R. Zakaria, J. Appl. Sci., 2011, 11, 3619-3624.

19 A. F. Zanette, R. A. Barella, S. B. C. Pergher, H. Treichel, D. Oliveira, M. A. Mazutti, E. A. Silva and J. V. Oliveira, Renew. Energy, 2011, 36, 726-731.

V. V. Bokade and G. D. Yadav, Ind. Eng. Chem. Res., 2009, 48, 9408-9415.

R. Ratti, S. Kaur, M. Vaultier and V. Singh, Catal. Commun., 2010, 11, 503-507.

22 B. Saha and M. Streat, React. Funct. Polym., 1999, 40, 13-27.

23 T. Issariyakul and A. K. Dalai, Energy \& Fuels, 2010, 24, 4652-4658.

24 H. Lauron-Pernot, Catal. Rev., 2006, 48, 315-361.

25 M.-L. Bailly, G. Costentin, H. Lauron-Pernot, J. M. Krafft and M. Che, J. Phys. Chem. $B, 2005,109,2404-13$.

26 O. Hiroaki, K. Hiroki and T. Atsushi, Phosphorus Res. Bull., 2008, 22, 27.

27 P. Putanov, E. Kis, G. Boskovic and K. Lázár, Appl. Catal., 1991, 73, 17-26.

28 A. G. Kalampounias, N. Bouropoulos, K. Katerinopoulou and S. N. Yannopoulos, $J$. Non. Cryst. Solids, 2008, 354, 749-754. 
O. T. Ozgul and O.-Y. Sevil, Eur. J. Lipid Sci. Technol., 2008, 110, 742-746.

30 M. Jaber, T. Georgelin, H. Bazzi, F. Costa-Torro, J.-F. Lambert, G. Bolbach and G. Clodic, J. Phys. Chem. C, 2014, 118, 25447-25455.

31 L. A. O’Dell and R. W. Schurko, Chem. Phys. Lett., 2008, 464, 97-102.

32 D. Massiot, F. Fayon, M. Capron, I. King, S. Le Calvé, B. Alonso, J.-O. Durand, B. Bujoli, Z. Gan and G. Hoatson, Magn. Reson. Chem., 2002, 40, 70-76.

33 International Union of Pure and Applied Chemistry, 2012.

34 H. Petitjean, H. Guesmi, H. Lauron-Pernot, G. Costentin, D. Loffreda, P. Sautet and F. Delbecq, ACS Catal., 2014, 4, 4004-4014.

35 M. A. Aramendía, V. Borau, C. Jiménez, J. M. Marinas, R. Roldfin, F. J. Romero and F. J. Urbano, in Studies in Surface Science and Catalysis, Elsevier, 2000, vol. Volume 143, pp. 899-906.

36 M. A. Aramendía, V. Borau, C. Jiménez, J. M. Marinas and F. J. Romero, J. Colloid Interface Sci., 1999, 217, 288-298.

37 L. Novikova, F. Roessner, L. Belchinskaya, M. AlSawalha and V. Krupskaya, Appl. Clay Sci., 2014, 101, 229-236.

38 M. A. Olutoye, S. W. Wong, L. H. Chin, H. Amani, M. Asif and B. H. Hameed, Renew. Energy, 2016, 86, 392-398.

39 S. A. Walling and J. L. Provis, Chem. Rev., 2016, 116, 4170-4204.

40 F. Jin and A. Al-Tabbaa, Cem. Concr. Compos., 2014, 52, 27-33.

41 C. Roosz, S. Grangeon, P. Blanc, V. Montouillout, B. Lothenbach, P. Henocq, E. Giffaut, P. Vieillard and S. Gaboreau, Cem. Concr. Res., 2015, 73, 228-237.

42 W.-S. Chiang, G. Ferraro, E. Fratini, F. Ridi, Y.-Q. Yeh, U.-S. Jeng, S.-H. Chen and P. Baglioni, J. Mater. Chem. A, 2014, 2, 12991-12998.

43 M. Tonelli, F. Martini, L. Calucci, E. Fratini, M. Geppi, F. Ridi, S. Borsacchi and P. Baglioni, Dalt. Trans., 2016, 45, 3294-3304.

44 K. Narasimharao, T. T. Ali, S. Bawaked and S. Basahel, Appl. Catal. A Gen., 2014, 488, 208-218.

45 B. Lothenbach, D. Nied, E. L'Hôpital, G. Achiedo and A. Dauzères, Cem. Concr. Res., 2015, 77, 60-68.

46 D. Nied, K. Enemark-Rasmussen, E. L'Hopital, J. Skibsted and B. Lothenbach, Cem. Concr. Res., 2016, 79, 323-332.

47 S. A. Walling, H. Kinoshita, S. A. Bernal, N. C. Collier and J. L. Provis, Dalt. Trans., 2015, 44, 8126-8137.

48 J.-B. d'Espinose de la Caillerie, M. Kermarec and O. Clause, J. Phys. Chem., 1995, 99, 17273-17281.

49 M. Magi, E. Lippmaa, A. Samoson, G. Engelhardt and A. R. Grimmer, J. Phys. Chem., $1984, \mathbf{8 8}, 1518-1522$.

50 D. R. M. Brew and F. P. Glasser, Cem. Concr. Res., 2005, 35, 85-98.

51 J. C. C. Freitas and M. E. Smith, in Annual Reports on NMR Spectroscopy, 2012, vol. 75, pp. 25-114. 
52 J. M. Griffin, A. J. Berry and S. E. Ashbrook, Solid State Nucl. Magn. Reson., 2011, 40, 91-99.

53 J.-B. d'Espinose de Lacaillerie, C. Fretigny and D. Massiot, J. Magn. Reson., 2008, 192, 244-251.

54 G. J. Rosasco and J. J. Blaha, Appl. Spectrosc., 1980, 34, 140-144.

55 T. F. Dossin, M.-F. Reyniers and G. B. Marin, Appl. Catal. B Environ., 2006, 62, 35 45.

56 G. Busca, Heterog. Catal. Mater., 2014, 103-195.

57 J. W. Kriesel and T. D. Tilley, J. Mater. Chem., 2001, 11, 1081-1085.

58 J. E. House and K. A. Kemper, J. Therm. Anal., 1987, 32, 1855-1858.

59 S. Russo and C. Noguera, Surf. Sci., 1992, 262, 245-258.

60 S. R. Kass, J. Am. Chem. Soc., 2005, 127, 13098-9. 


\section{Scheme 1}

Reactivity of $\mathrm{MBOH}$ on various sites. ${ }^{[24]}$

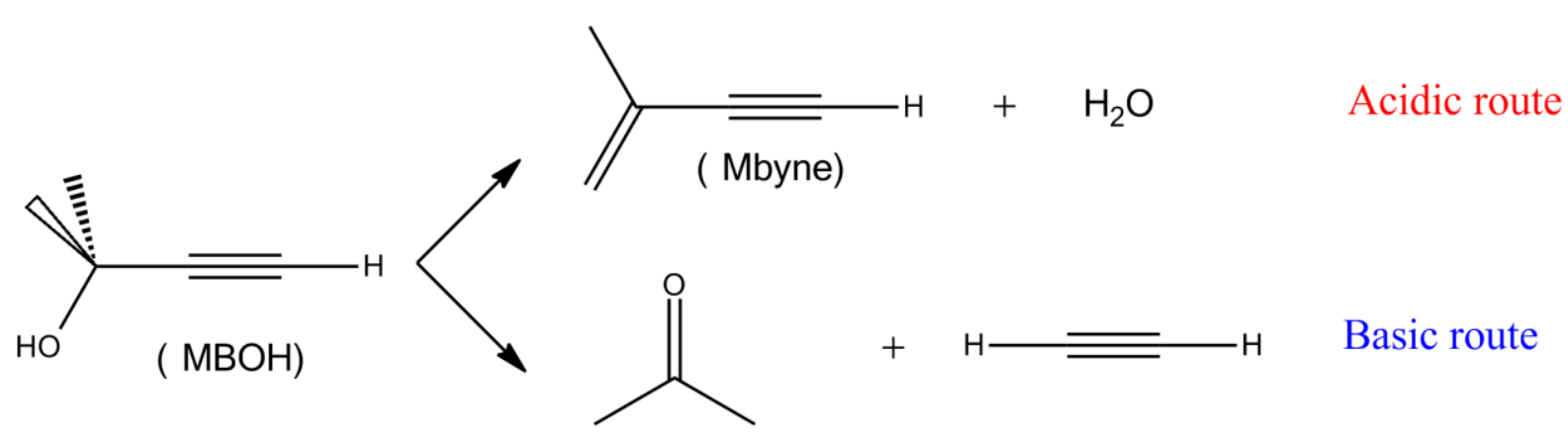




\section{Scheme 2}

Structure of a defective talc sheet, with oxygen covalently bound in orange and oxygen without bond to $\mathrm{Si}$ in blue. Hydrogen atoms are omitted on this scheme.

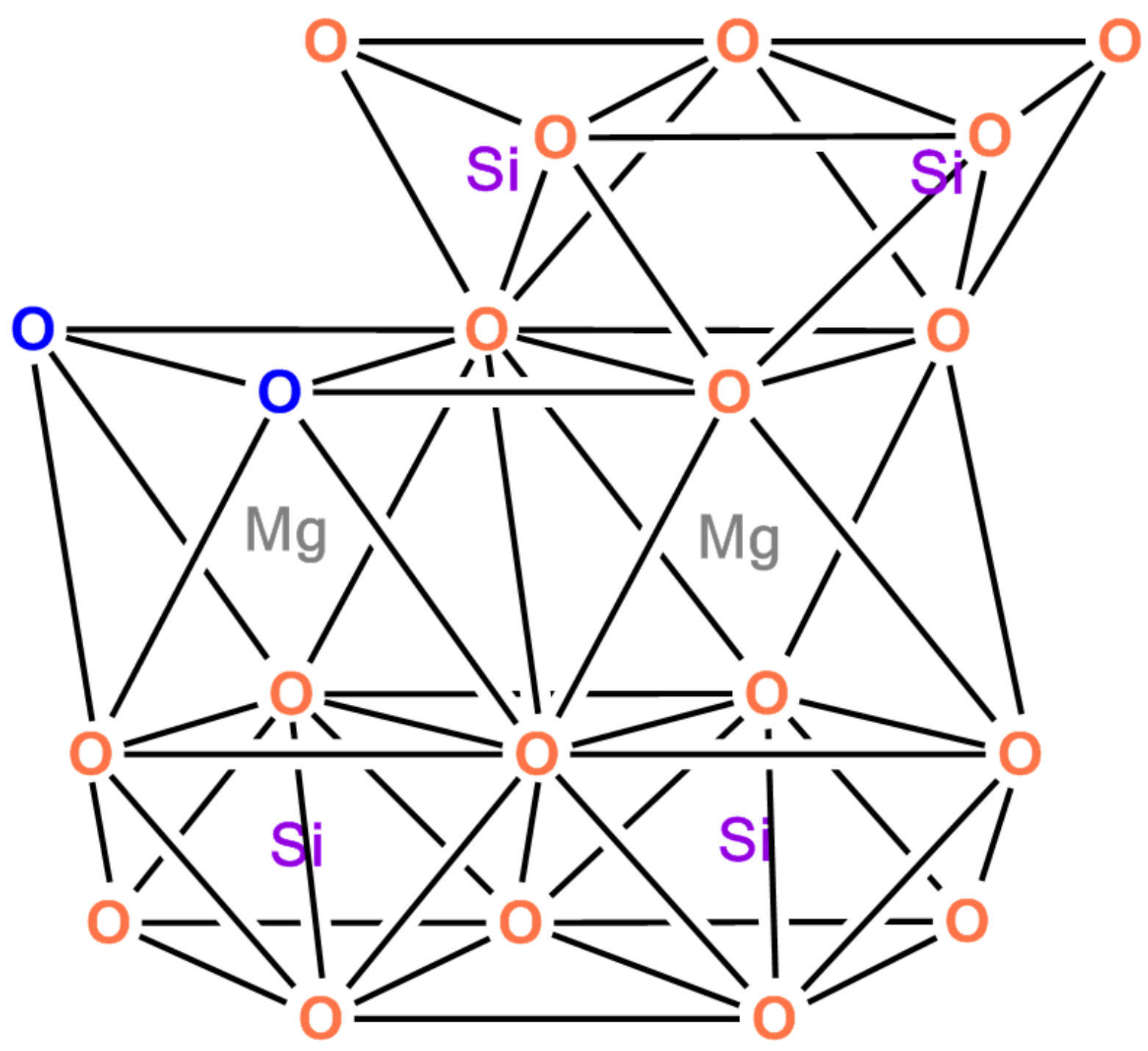


Table 1a

Specific surface area and protonic affinity of some magnesium based solids used in the study

\begin{tabular}{|c|c|c|}
\hline Solid & $\begin{array}{l}\text { Specific surface area } \\
\qquad\left(\mathbf{m}^{2} \cdot \mathrm{g}^{-1}\right)\end{array}$ & $\begin{array}{l}\text { Protonic affinity of the base } \\
\qquad\left(\mathrm{kJ} \cdot \mathrm{mol}^{-1}\right)\end{array}$ \\
\hline MgO & 150 & $2318^{[58]}$ or $2576^{[59]}$ \\
\hline $\mathrm{MgCO}_{3}$ & 57 & $2261^{[58]}$ \\
\hline $\operatorname{Mg}(\mathrm{OH})_{2}$ & 33 & $1590^{[59]}$ \\
\hline $\mathrm{MgC}_{2} \mathrm{O}_{4}$ & 121 & $1857^{[60]}$ \\
\hline $\mathrm{Mg}_{3}\left(\mathrm{PO}_{4}\right)_{2}$ & 109 & - \\
\hline
\end{tabular}


Table 1b

Specific surface area and $\mathrm{Mg} / \mathrm{Si}$ ratio of the magnesium silicates

\begin{tabular}{|c|c|c|c|}
\hline Solid & $\begin{array}{c}\text { Specific surface } \\
\text { area } \\
\left(\mathbf{m}^{2} \cdot \mathbf{g}^{-1}\right)\end{array}$ & $(\mathbf{M g} / \mathbf{S i})$ molar ratio (XRF) & $(\mathbf{M g} / \mathbf{S i})$ molar ratio (XPS) \\
\hline Mg Silicate (com) & 421 & 0.290 & 0.485 \\
\hline $\begin{array}{c}\text { Mg Silicate } \\
(\mathbf{c p})\end{array}$ & 447 & 0.268 & 0.450 \\
\hline $\begin{array}{c}\text { Mg Silicate } \\
\text { (sg) }\end{array}$ & 295 & 0.321 & 0.332 \\
\hline \begin{tabular}{c} 
Montmorillonite \\
\hline
\end{tabular} & 160 & - & - \\
\hline
\end{tabular}




\section{Figure 1}

Conversions (\%) of $\mathrm{MBOH}$ following the acidic and basic route. The conversion was obtained at $393 \mathrm{~K}$ (figure 1a) and $433 \mathrm{~K}$ (figure $1 \mathrm{~b}$ ). The numbers written within parenthesis are the conversion normalized per surface unit $\left(\%\right.$.g. $\left.\mathrm{m}^{-2}\right)$ when the conversion was low enough for this parameter to be meaningful.

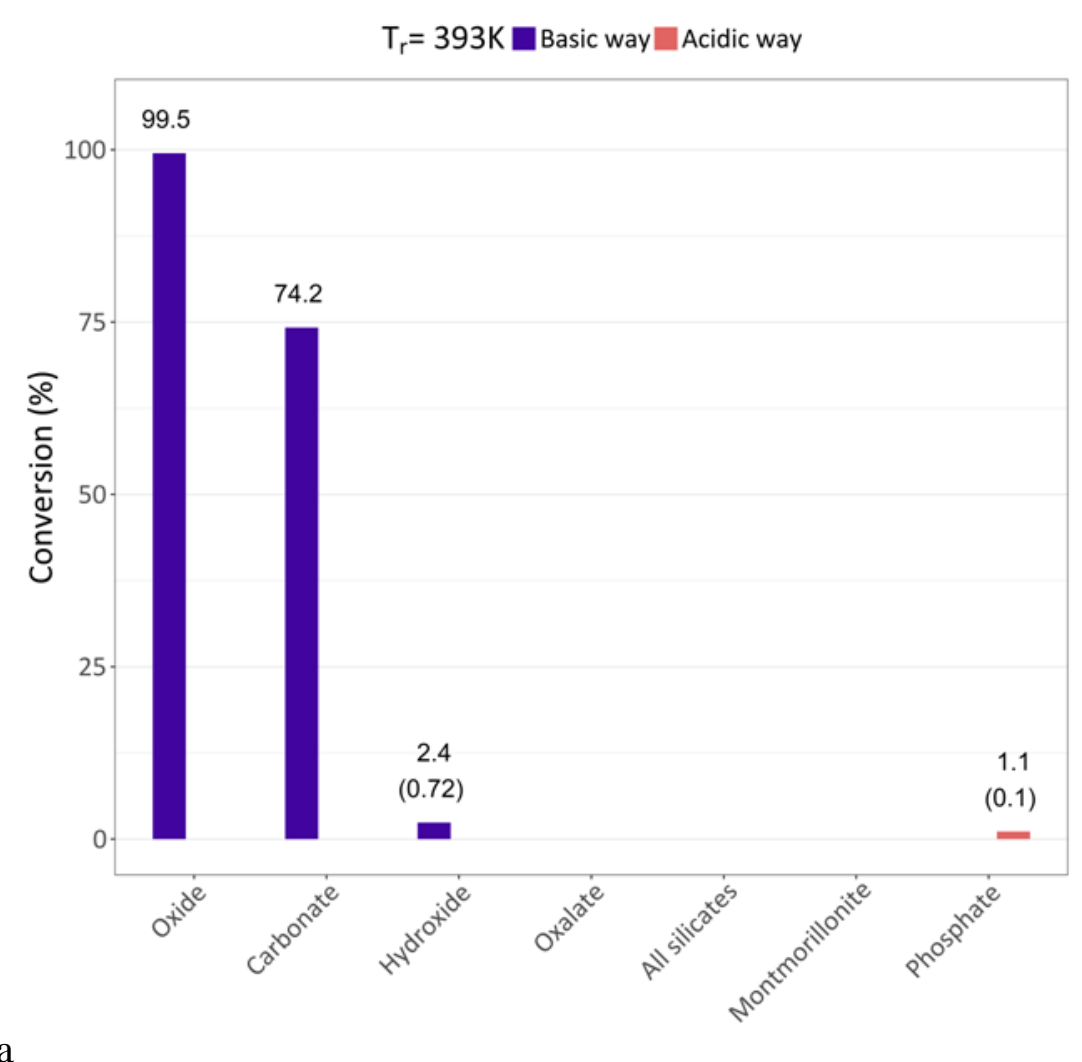

a 


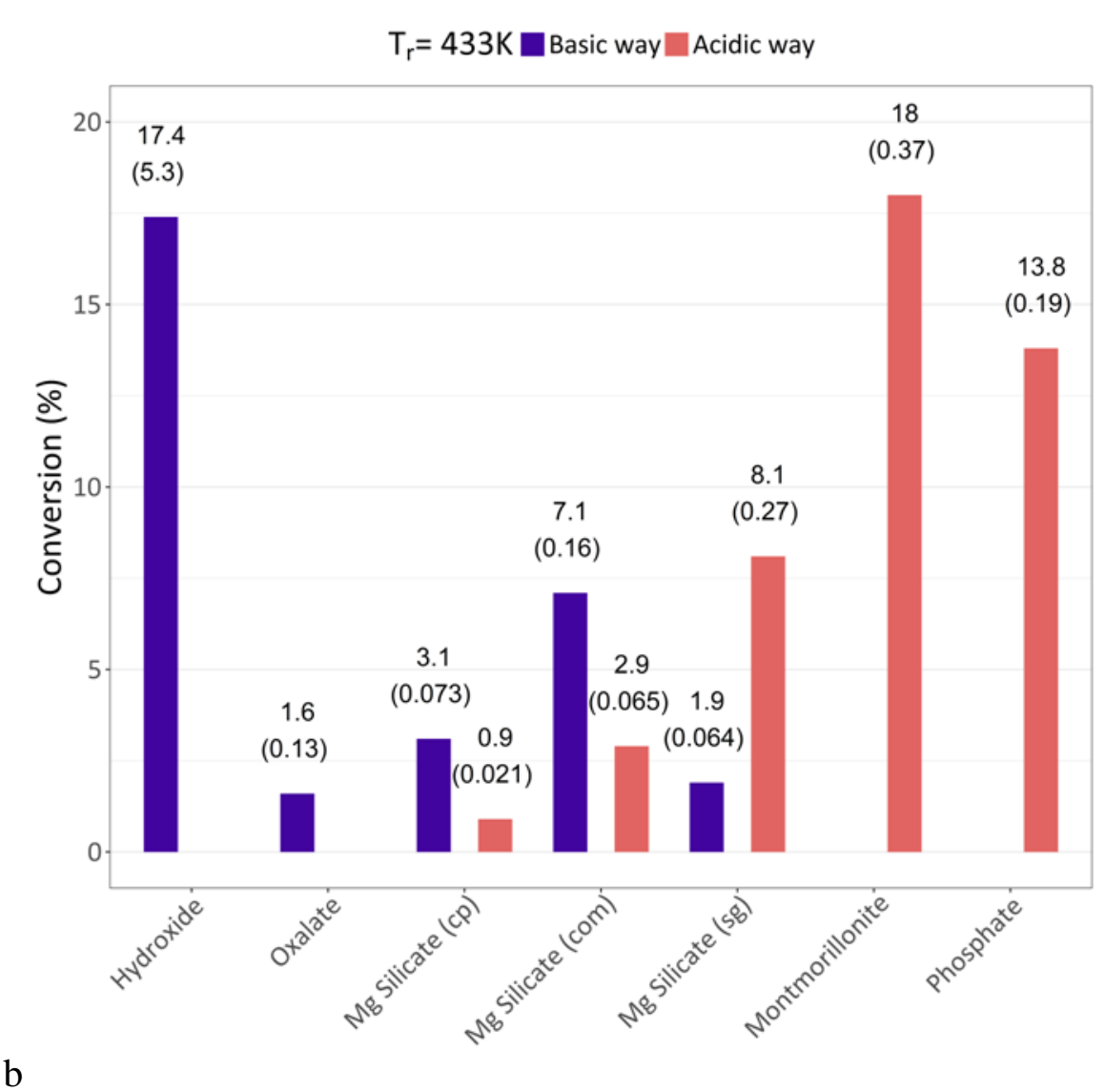




\section{Figure 2}

Conversions (\%) for transesterification in liquid $(333 \mathrm{~K})$ and gas $(393 \mathrm{~K})$ phases. The numbers written within parenthesis are the conversion normalized per surface unit (\%o.g.m ${ }^{-2}$ ) when the conversion was low enough for this parameter to be meaningful.

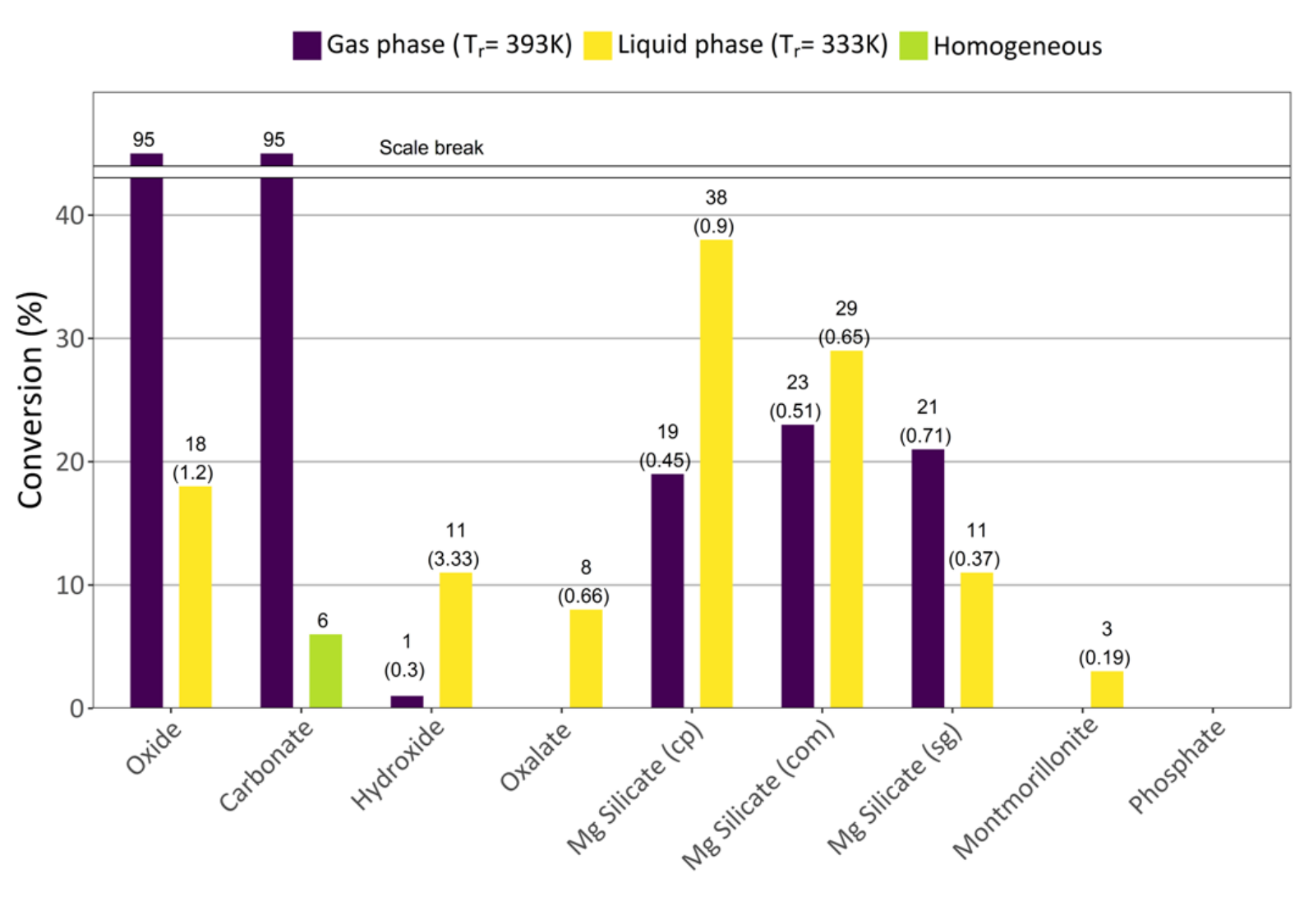




\section{Figure 3}

XRD patterns of the Mg silicates

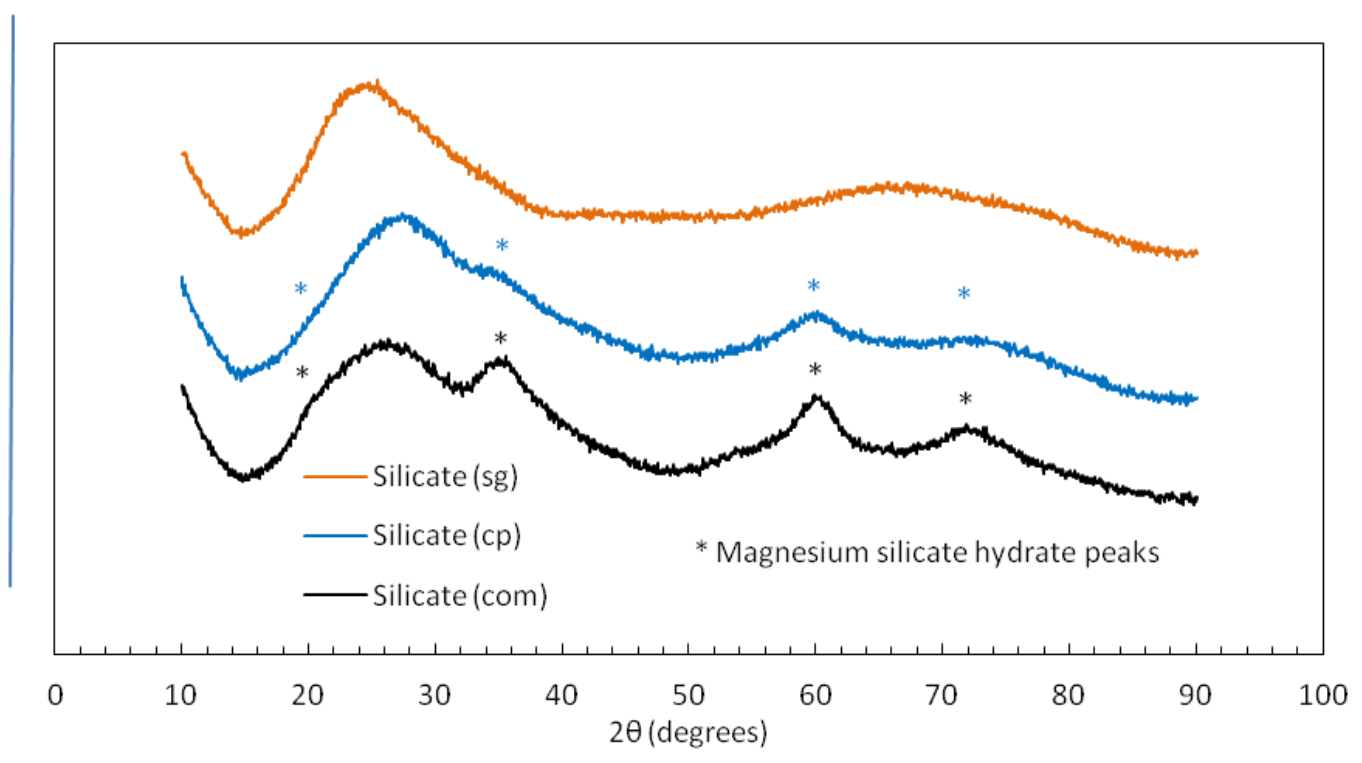

Figure 4

${ }^{29} \mathrm{Si}$ DP MAS NMR spectra of (A) Mg silicate (com), (B) (cp) and (C) (sg).

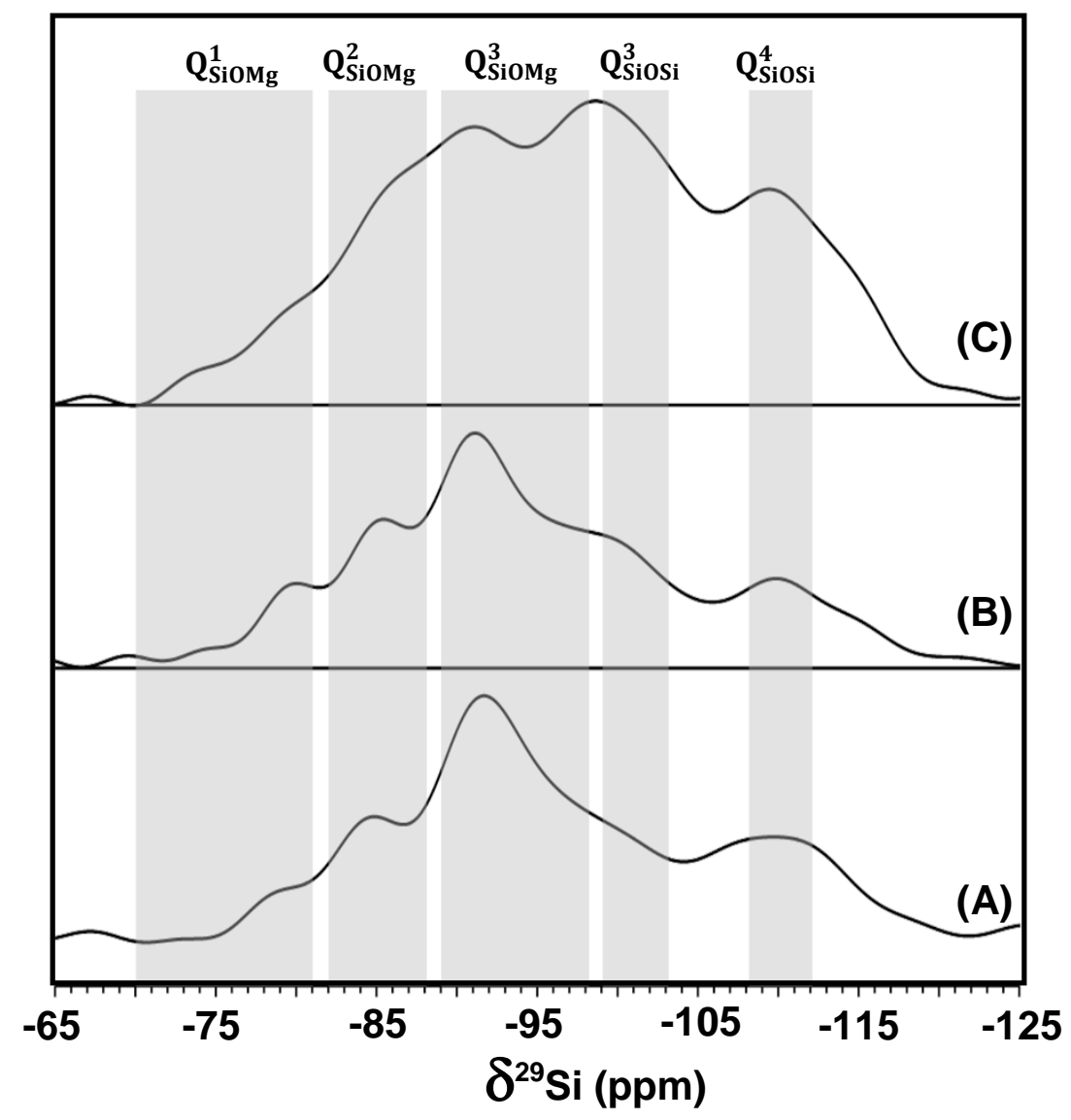




\section{Figure 5}

${ }^{25} \mathrm{Mg}$ WURST-QCPMG NMR spectra of (A) Mg silicate (com), (B) (cp) and (C) (sg). Experimental spectra are composed by spikelet spectrum (bottom) and simulated spectrum (top). The spectra "FIT" are the optimum decomposition obtained with Dmfit software

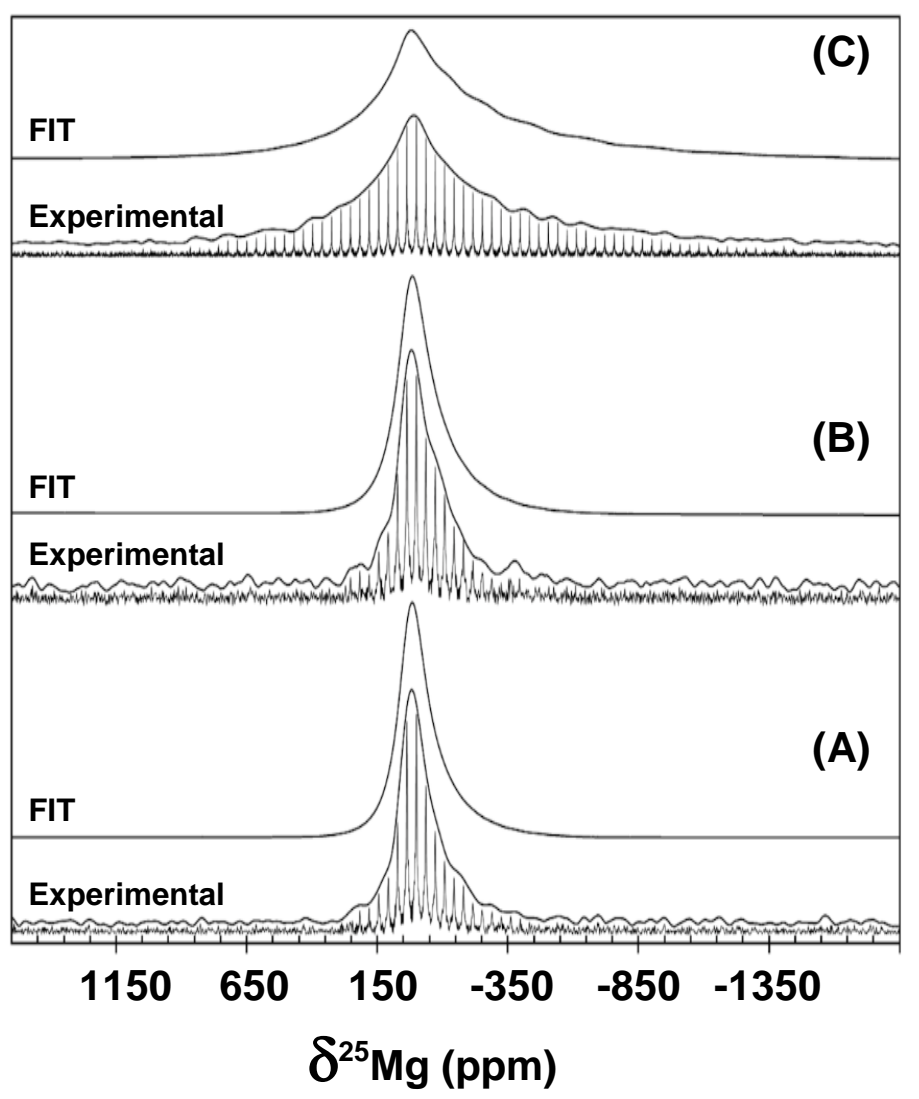


Figure 6

DRIFT spectra of the $\mathrm{Mg}$ silicates at $413 \mathrm{~K}$ after pretreatment at $623 \mathrm{~K}$.

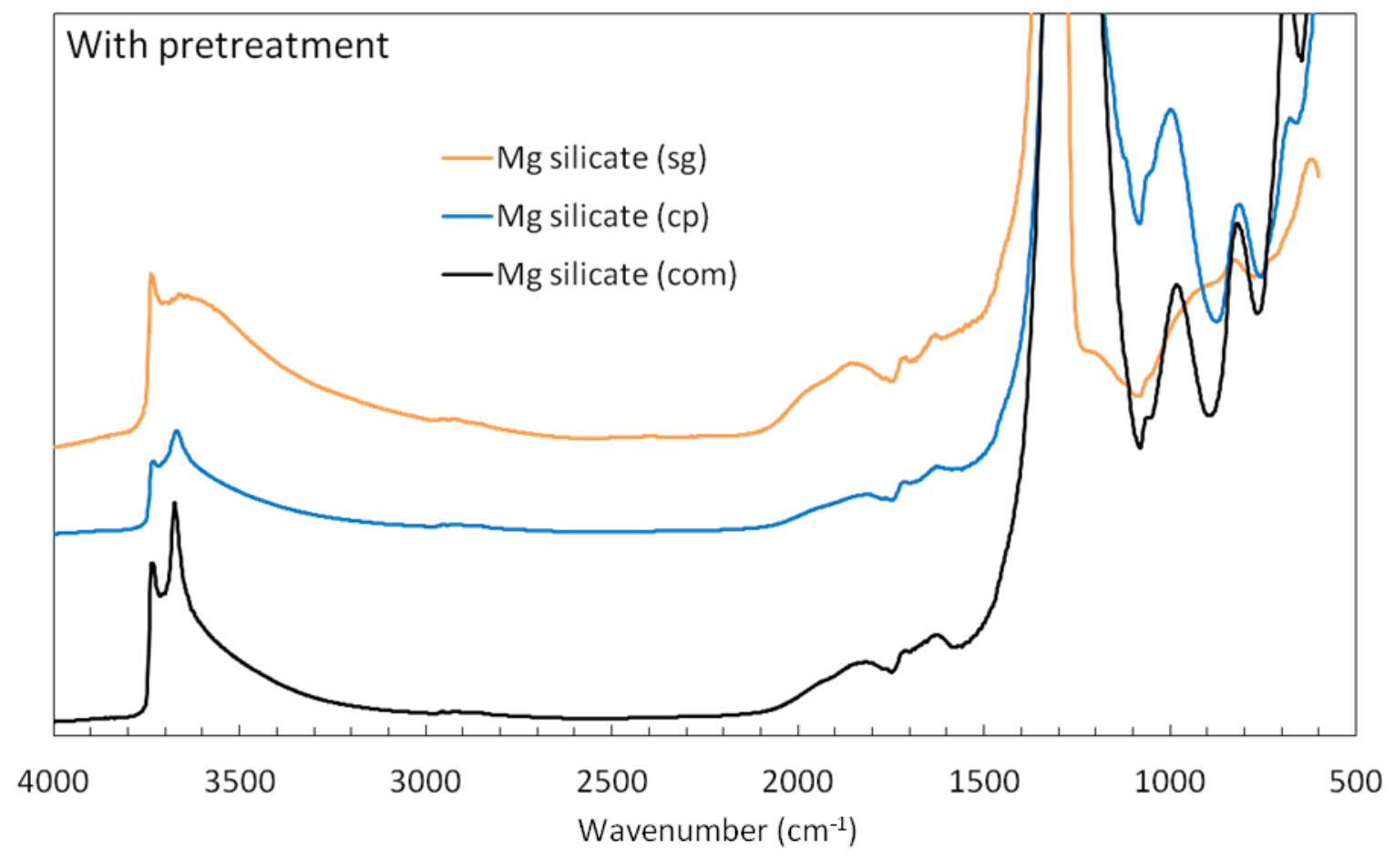

